NBSIR $77-862$

DO NOT REMOND

\title{
STUDIES OF HYDROGEN LIQUEFIER EFFICIENCY AND THE RECOVERY OF THE LIOUEFACTION ENERGY
}

R.O. Voth

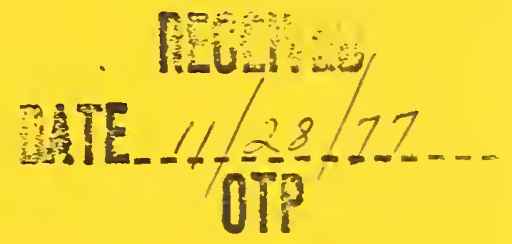

W.R. Parrish

Cryogenics Division

Institute for Basic Standards

National Bureau of Standards

Boulder, Colorado 80302 


\section{STUDIES OF HYOROGEN LIOUEFIER EFFICIENCY AND THE RECOVERY OF THE LIOUEFACTION ENERGY}

R.O. Voth

W.R. Parrish

Cryogenics Division Institute for Basic Standards

National Bureau of Standards

Boulder, Colorado 80302

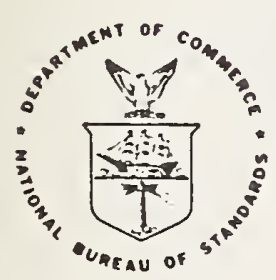

U.S. DEPARTMENT OF COMMERCE, Juanita M. Kreps, Secretary Sidney Harman, Under Secretary Jordan J. Baruch, Assistant Secretary for Science and Technology 
• 
CHAPTER 1. HYDROGEN IIQUEFIER EFFICIENCY

R. O. Voth

1. SUMMARY

1.1. Introduction

1.2. Derivation of the Defined Cycle

1.2.1. Losses due to expander and compressor inefficiency . . . . . . . . . . . 6

1.2.2. Losses due to heat exchanger temperature

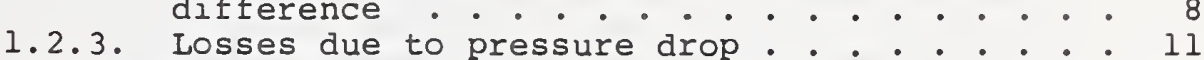

1.2.4. Multipressure liquefaction cycles... . . . 11

1.3. The Real Hydrogen Liquefier... . . . . . . . . . 11

1.3.1. Efficiency and losses of real liquefier components . . . . . . . . . . . . 15

1.3.1.1. Compressor . . . . . . . . . 15

1.3.1.2. Expanders ............ . 16

1.3.1.3. Joule-Thomson expansion valve.. . 17

1.3.1.4. Expansion ejector valve..... 17

1.3.1.5. Heat exchangers . . . . . . . 19

1.3.2. Real hydrogen liquefier cycle....... 19

1.3.2.1. The design of a practical

hydrogen liquefier . . . . . . 32

1.4. Comparison Between Defined Cycle and Real Gas

Cycle . . . . . . . . . . . . . . . . 35

1.5. Conclusions . . . . . . . . . . . . . . 35

1.6. Nomenclature .. . . . . . . . . . . . 39

1.7. References . . . . . . . . . . . . . . 41

1.8. APPENDIX - Hydride Compressors . . . . . . . . . 42

1.8.1. Introduction . . . . . . . . . . . . 42

1.8.2. Properties of metal hydrides . . . . . . . 42

1.8.3. Hydride compressor system . . . . . . . 42

CHAPTER 2. RECOVERY OF HYDROGEN LIQUEFACTION ENERGY . • . . . • • . . . 45

W. R. Parrish

2. SUMMARY

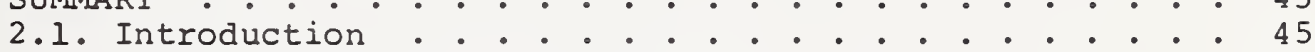

2.2. Electrical Utility Applications . . . . . . . . . 46

2.2.1. Iiquefaction energy recovery factor . . . . 46

2.2.2. Liquefaction energy recovery systems . . . . 47

2.3. Recovery of Rare Gases . . . . . . . . . . . . 51

2.3.1. Helium recovery process... . . . . . . 52

2.3.2. Work limitations. . . . . . . . . . . . 52

2.3.3. Refrigeration limitations . . . . . . . . 53

2.4. Conclusions . . . . . . . . . . . . . . . 53

2.4.1. Utility application... . . . . . . . . 53

2.4.2. Rare gas recovery . . . . . . . . . . 53

2.5. References . . . . . . . . . . . . . . 54

2.6. APPENDIX - Air Plant Design . . . . . . . . . . 55

2.6.1. Design using an atmospheric column . . . . 55

2.6.2. Subatmospheric column . . . . . . . . 57 
Iiquid hydrogen is a potential synthetic fuel. It is nonfossil, its production and storage technology is well developed, and it is inherently nonpolluting. However, the economics of liquefying hydrogen are costly both in the energy required to produce the liquid and in the capital costs of the liquefier. These costs could be reduced by increasing the liquefier efficiency and/or by recovering a portion of the liquefaction energy at the use site. This paper provides the maximum hydrogen liqlefier efficiency based on the efficiency of available components and the fraction of original liquefaction energy that can be recovered at the use site. Since the inefficient compressors and expanders are the major cause of liquefier inefficiency, no increase in Iiquefier efficiency above the current 30 to 35 percent is probable without a corresponding increase in compressor and expander efficiency --a difficult task since both the compressors and expanders have a long and stable history of development. However, roughly one-third to one-half of the actual energy required to liquefy hydrogen can be recovered at the use site and this represents a cost credit for liquid hydrogen.

Key words: Component efficiency; cryogenics; efficiency; energy recovery; hydrogen; liguefier. 


\title{
HYDROGEN LIQUEFIER EFFICIENCY
}

\author{
R. O. Voth
}

\section{SUMMARY}

The efficiency of current hydrogen liquefiers lies in the range of 30 to 35 percent of Carnot. Since this efficiency appears low when it is compared to other thermodynamic cycles, this study was undertaken to determine the maximum possible efficiency for large capacity mechanical liquefiers using state-of-the-art compressors, expanders, and heat exchangers. Two approaches were used to determine the maximum efficiency. The first approach employs a defined liquefaction cycle that uses an ideal gas working fluid. Although the working fluid is ideal, the real effects on liquefier efficiency of heat exchanger temperature difference, system pressure drop, and component efficiency can be determined. The second approach uses hydrogen properties in practical cycles to determine maximum liquefier efficiency. With a real gas working fluid the final expansion device could be a Joule Thomson valve, an expansion ejector or a wet expander (the exhaust of the expander contains liquid) instead of the theoretical isothermal expander of the defined cycle.

The maximum liquefier efficiency found from the two approaches agreed closely and they were in the range of 30 to 35 percent. Because the compressors and expanders were the major sources of inefficiency, no increase in liquefier efficiency is probable without a corresponding increase in the compressor or expander efficiency -- a difficult task since both the compressors and expanders have a long and stable history of development. Consequently, higher liquefier efficiencies are not probable in the near future.

Because of the large dependence of the liquefier efficiency on compressor efficiency, a metal hydride compressor was investigated. The heat required by the hydride compressor was obtained from the waste heat of a parallel mechanical compressor. However, because of the low quality of this heat, the hydride compressor did not contribute significantly to an increase in the overall efficiency of the compressor system.

\subsection{Introduction}

The cost of producing liquid from gaseous hydrogen is an economic barrier to the early adoption of liquid hydrogen as an "energy carrier". Decreasing the liquefaction costs is partially dependent on increasing the efficiency of the liquefaction process above the current 30 to 35 percent [1]. This study investigates the efficiency of hydrogen liquefiers in the following manner:

1) By using a defined cycle with a perfect gas working fluid, the maximum efficiency of the liquefier as a function of the efficiency of the liquefier components is established. The defined cycle efficiency -- the cycle is reversible for reversible components -includes the effects of component inefficiency, system pressure drop, and heat exchanger temperature difference.

2) The efficiencies of practical cycles with a real-gas (hydrogen) working fluid are determined and compared to the defined cycle efficiencies. The practical liquefier is designed for maximum efficiency using a Joule Thomson expansion valve, an expansion ejector, or a wet expander as the final expansion device. The comparable efficiencies found by the defined cycle and the practical liquefier, shows that the penalty in efficiency associated with the use of a real gas can be made small with appropriate cycle selection. 
As a result of these calculations, the inefficiency of the compressors and expanders are shown to have the most influence on the overall liquefier efficiency.

An unsuccessful attempt to increase the efficiency of the compressor by the use of a metal hydride is shown in Appendix A. Without an increase in compressor or expander efficiency, the current hydrogen liquefier efficiencies of 30 to 35 percent of Carnot will not be increased significantly. in the future.

\subsection{Derivation of the Defined Cycle}

The analysis of a hydrogen liquefaction cycle is a complex thermodynamic and economic problem. The thermodynamic complexity results from the nonideal properties of hydrogen. For example, simple first law analysis does not uncover negative heat exchanger temperature differences dictated by the variable specific heats in the real gas when invalid boundary conditions are chosen Therefore, it is necessary to perform a more complex numerical analysis of the system heat exchangers. Variable properties also require optimization of pressure ratios and temperature inlets for the expanders used in the system.

The analysis must also include economics. For example, a heat exchanger designed for small temperature differences will increase the overall cycle efficiency but require an increased capital expenditure. The usual approach to cycle studies is to make a parametric study of the liquefaction cycle using a computer and then to choose one of the calculated cycles that is compatible with available components. Although this approach gives exact results, one is never quite sure that a different (and unconsidered) cycle might not yield a superior efficiency.

By using a simple defined cycle which is reversible for reversible components, we are able to easily evaluate the effect of various system components, and to make a reasonably accurate estimate of the maximum possible cycle efficiency with components of given efficiencies.

Liquefier efficiency is based on the equation:

$$
\eta_{C y}=\frac{\text { Ideal power requirements }}{\text { Actual net power requirements }}
$$

The net power required by the cycle is the required compressor power less the recoverable power from the expanders. The cycle efficiency should be 100 percent when the components in the cycle are ideal and the effect of component losses in the cycle on cycle efficiency should be realistic.

By extending the earier work of collins [2] for an ideal liquefaction cycle, the defined cycle shown schematically in figure 1.1 is derived. The cycle uses a refrigeration loop to precool and condense a separate product stream. The refrigeration loop bypass turbines are situated so the inlet temperature of each expander is higher than the discharge temperature of the preceding expander by the temperature difference of the heat exchanger. The heat exchanger temperature difference is proportional to the absolute temperature as defined by a constant $C=\Delta T / T$. The final expander in the refrigeration loop is a theoretical isothermal expander used to condense the product stream. Both the refrigerant and the product streams are perfect gases with constant specific heats. The product stream condenses at $T_{C}$ with a latent heat $28.988 \mathrm{~K}$ times the specific heat (i.e., the same ratio as for hydrogen). Changing the latent heat ratio and the value of $\mathrm{T}_{\mathrm{C}}$ would make the defined cycle applicable to other fluids. The high temperature (heat rejection) end of the cycle $\left(\mathrm{T}_{\mathrm{H}}\right.$ figure 1.1$)$ is taken as $300 \mathrm{~K}$ in the calculations, while the cold end temperature $\left(\mathrm{T}_{\mathrm{C}}\right)$ was taken as $20.268 \mathrm{~K}$, the normal boiling point of liquid parahydrogen. 


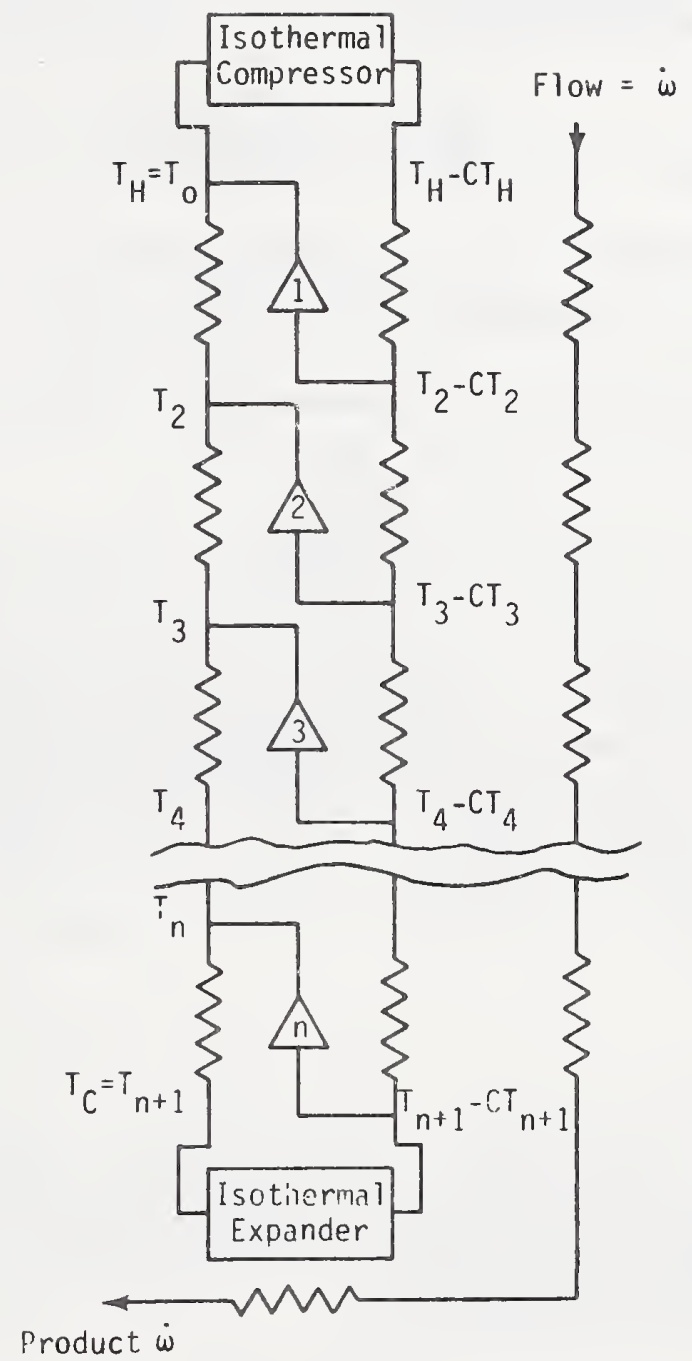

Figure 1.1. Schematic of the defined cycle. 
The arrangement of the expanders in the precooling portion of the cycle (figure 1.1), is the most efficient arrangement because the refrigeration required by the product stream is exactly matched at each temperature by the refrigeration produced by the expanders. For reversible expanders and heat exchangers, this arrangement is reversible. For finite size heat exchangers, balanced flow maintains a constant heat exchanger temperature difference, and the flow through each expander is the same as the product stream flow, w. In order to maintain $\Delta \mathrm{T} \sim \mathrm{T}$ in the heat exchanger (which minimizes the heat exchanger losses [3]), a slight imbalance in the flow is required, resulting in a slightly greater expander flow.

Returning to the definition of cycle efficiency (equation 1.2.1), the cycle efficiency can be written as

where

$$
\eta_{c y}=\frac{w_{c i}}{w_{c a}-w_{E}} \text {, }
$$

$$
\begin{aligned}
& n_{C y}=\text { the overall cycle efficiency based on } w_{C i}, \\
& w_{C i}=\text { ideal liquefier power requirements, } \\
& w_{C a}=\text { actual total compressor power, and } \\
& w_{E}=\text { the recoverable expander power. }
\end{aligned}
$$

The expander output can be recovered by using it to drive either a booster compressor stage or an electrical generator to provide part of the power required by the main compressor. In either case, the power required by the liquefier is reduced by part of the expander output. In the first case the required compressor power is reduced by an amount equal to the expander power assuming an equal efficiency for both compressors. In the second case the recoverable expander power is less than the expander output due to the inefficiency of gear trains and the electrical generator. In the calculations presented here the total compressor power requirements were reduced by the total calculated expander power.

The ideal work of liquefaction is determined from the availability function of the product.

where

$$
\Psi=h_{1}-h_{0}-T_{0}\left(s_{1}-s_{0}\right)
$$

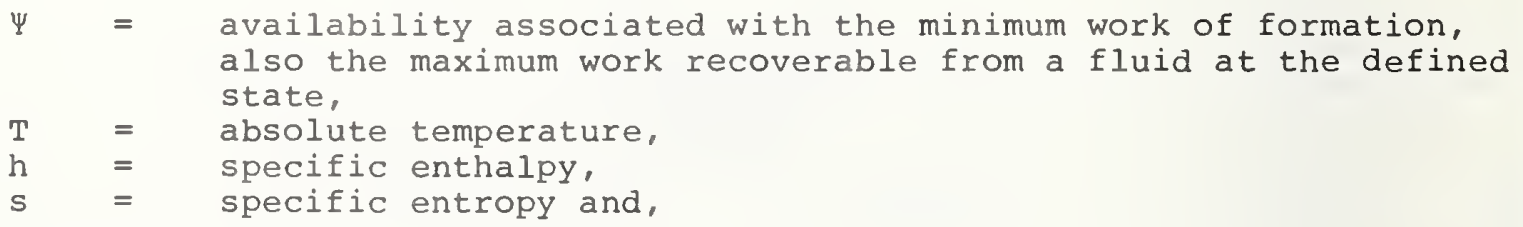

subscripts

1 = defined state - liquid hydrogen at 1 atmosphere,

0 = ambient conditions - 1 atmosphere pressure, $300 \mathrm{~K}$ temperature.

For a perfect gas system the ideal liquefaction power can be defined as the sum of: 1) the ideal power required to precool the product stream $\left(w_{1}\right)$, and 2) the ideal power required to condense the product $\left(W_{2}\right)$. Precooling the product stream occurs over a variable temperature, and the ideal work for this process is given by Jacobs [4] as, 


$$
W_{1}=\frac{T_{0}-T_{1 m}}{T_{1 m}} Q .
$$

where

$\mathrm{T}_{\mathrm{O}}=$ ambient temperature also equal to $\mathrm{T}_{\mathrm{H}}$ for the liquefier,

$\mathrm{T}_{1 \mathrm{~m}}=\left(\mathrm{T}_{\mathrm{H}}-\mathrm{T}_{\mathrm{C}}\right) / \ln \left(\mathrm{T}_{\mathrm{H}} / \mathrm{T}_{\mathrm{C}}\right)$,

${ }^{T_{C}}=$ lowest refrigeration temperature,

$Q=$ heat load equal to the product stream flow rate $(\dot{w})$ times $\mathrm{C}_{\mathrm{p}}\left(\mathrm{T}_{\mathrm{H}}-\mathrm{T}_{\mathrm{C}}\right)$, and

$C_{p}=$ constant pressure specific heat. comes,

By replacing $Q$, the ideal work for the variable temperature process be-

$$
\mathrm{w}_{1}=\frac{\mathrm{T}_{\mathrm{H}}-\mathrm{T}_{1 \mathrm{~m}}}{\mathrm{~T}_{1 \mathrm{~m}}} \dot{\omega} \mathrm{C}_{\mathrm{p}}\left(\mathrm{T}_{\mathrm{H}}-\mathrm{T}_{\mathrm{C}}\right) \text {. }
$$

The ideal power required to condense the fluid at a constant temperature is

$$
\mathrm{W}_{2}=Q\left(\frac{{ }_{\mathrm{H}}-\mathrm{T}_{C}}{{ }_{\mathrm{T}}}\right) \text {, }
$$

where

$$
\begin{aligned}
& Q=\lambda \times \dot{\omega}, \text { and } \\
& \lambda=\text { Latent heat. }
\end{aligned}
$$

Thus, the total ideal power required is,

$$
W_{C i}=\frac{T_{H}-T_{I m}}{{ }^{T} I m} \dot{\omega} C_{p}\left(T_{H}-T_{C}\right)+\dot{\omega}(\lambda)\left(\frac{T_{H}-T_{C}}{T_{C}}\right)
$$

or since $\lambda=28.988 \times \mathrm{C}_{\mathrm{p}^{\prime}}$

$$
\mathrm{w}_{C i}=\frac{\mathrm{T}_{H}-\mathrm{T}_{1 \mathrm{~m}}}{\mathrm{~T}_{1 \mathrm{~m}}} \dot{\omega} \mathrm{C}_{\mathrm{p}}\left(\mathrm{T}_{\mathrm{H}}-\mathrm{T}_{\mathrm{C}}\right)+28.988 \mathrm{C}_{\mathrm{p}} \dot{\omega}\left(\frac{\mathrm{T}_{\mathrm{H}}-\mathrm{T}_{\mathrm{C}}}{{ }_{\mathrm{T}} \mathrm{C}}\right) \text {. }
$$

Since the minimum compressor power is a result of a reversible isothermal process, compressor efficiencies used in the calculations are based on the ideal isothermal work of compression. For a perfect gas the isothermal compressor power is given by,

$$
W_{i}=\frac{\dot{\mathrm{m}} \mathrm{RT}_{\mathrm{H}} \text { en } \mathrm{Pr}}{\mathrm{n}_{\mathrm{C}}}
$$

where

$$
\begin{aligned}
& \mathrm{w}_{\dot{1}}=\text { isothermal compression power, } \\
& \dot{\mathrm{m}}=\text { mass flow through the compressor, } \\
& \mathrm{R}=\text { gas constant, }
\end{aligned}
$$




$\mathrm{T}_{\mathrm{H}}=$ compression temperature $\left(\mathrm{T}_{\mathrm{H}}=\mathrm{T}_{\mathrm{O}}\right)$,
$\mathrm{Pr}=$ pressure ratio (high pressure/low pressure), and
$\mathrm{n}_{\mathrm{C}}=$ isothermal efficiency of the compressor.

The total flow through the compressor is the sum of the flows through the expanders, and the total expander flow is a function of losses in the cycle. These losses are a result of the inefficiency of the expanders, of heat exchanger temperature differences and of system prossure drop. Each of these loss effects will be covered separately.

\subsubsection{Losses due to expander and compressor inefficiency}

In this section only the losses from inefficient expanders and compressors will be considered. The heat exchangers have zero temperature differences and there is no system pressure drop.

The losses incurred by inefficient precooling expanders are a result of a less than ideal temperature drop across the expanders. This decreased temperature drop increases the number of expanders required in the precooling portion of the liquefier thereby increasing the compressor flow rate. Flow through the isothermal expander also increases with decreasing efficiency. With zero temperature difference in the heat exchanger, the flow through each precooling expander is equal to the product stream flow. Thus, the compressor flow due to the precooling expanders becomes

$$
\dot{\mathrm{m}}_{\mathrm{pre}}=\mathrm{N}_{\exp } \times \dot{\omega}
$$

where

$$
\begin{aligned}
& \dot{\mathrm{m}}_{\text {pre }}=\text { total mass flow rate through the precooling expanders, and } \\
& \mathrm{N}_{\text {exp }}=\text { number of precooling expanders. }
\end{aligned}
$$

The temperature drop across an expander operating with a perfect gas is

where

$$
\mathrm{T}_{\text {in }}-\mathrm{T}_{\text {out }}=\eta_{\text {pre }} \mathrm{T}_{\text {in }}\left(1-\mathrm{Pr}^{-\alpha}\right)
$$

$$
\begin{array}{ll}
\mathrm{T}_{\text {in }}= & \text { the expander inlet temperature, } \\
\mathrm{T}_{\text {out }}= & \text { the expander outlet temperature, } \\
\eta_{\text {pre }}= & \text { isentropic efficiency of the precooling expanders, } \\
\operatorname{Pr}= & \text { pressure ratio across the expander, } \\
\alpha \quad & (\mathrm{k}-1) / \mathrm{k}, \text { and } \\
\mathrm{k} & =\text { ratio of specific heats ( } 1.404 \text { for hydrogen at ambient tempera- }
\end{array}
$$
From figure 1.1 , expressions for $\mathrm{T}_{2}, \mathrm{~T}_{3},--\mathrm{T}_{\mathrm{n}+1}$ can be written based on the
expander efficiencies as follows

$$
\begin{aligned}
\mathrm{T}_{2} & =\mathrm{T}_{\mathrm{H}}\left(1-n_{\text {pre }}+\eta_{\text {pre }} \operatorname{Pr}^{-\alpha}\right) \\
\mathrm{T}_{3} & =\mathrm{T}_{2}\left(1-\eta_{\text {pre }}+n_{\text {pre }} \operatorname{Pr}^{-\alpha}\right)--- \\
\mathrm{T}_{\mathrm{n}+1} & =\mathrm{T}_{\mathrm{n}}\left(1-\eta_{\text {pre }}+n_{\text {pre }} \operatorname{Pr}^{-\alpha}\right) .
\end{aligned}
$$


Assuming the same efficiency for all the precooling expanders and substituting to maintain $\mathrm{T}_{\mathrm{H}}$ in the equation yields,

$$
\mathrm{T}_{\mathrm{n}+1}=\mathrm{T}_{\mathrm{C}}=\mathrm{T}_{\mathrm{H}}\left(1-\eta_{\text {pre }}+\eta_{\text {pre }} \mathrm{Pr}^{-\alpha}\right)^{{ }^{\mathrm{N}} \exp } \text {. }
$$

Solving for the number of expanders ( $\mathrm{N}_{\text {exp }}$ ) results in

$$
N_{\exp }=\frac{\ln \left(\frac{{ }^{T_{C}}}{\mathrm{~T}_{H}}\right)}{\ln \left(1-n_{\text {pre }}+\eta_{\text {pre }} \operatorname{Pr}^{-\alpha}\right)} .
$$

If the expanders are reversible, the equation reduces to

$$
N_{\exp }=\frac{\ln \left(\frac{\mathrm{T}_{\mathrm{C}}}{\mathrm{T}_{\mathrm{H}}}\right)}{\ln \left(\mathrm{Pr}^{-\alpha}\right)} .
$$

The recoverable power from each precooling expander becomes,

$$
W_{\text {pre }}=\dot{\omega} C_{p}\left(T_{\text {in }}-T_{\text {out }}\right) \text {, }
$$

or summing from $T_{H}$ down to $T_{C}$, the total recoverable power becomes

$$
\mathrm{W}_{\mathrm{R}_{\text {pre }}}=\dot{\omega} \mathrm{C}_{\mathrm{p}}\left(\mathrm{T}_{\mathrm{H}}-\mathrm{T}_{\mathrm{C}}\right) \text {. }
$$

The mass flow through the isothermal expander is related to the expander efficiency and the flow and latent heat of the product stream as,

$$
\dot{m}_{\text {iso }}=\frac{28.988\left(C_{p}\right)(\dot{w})}{n_{\text {iso }}{ }^{T_{C}^{R} \ln \text { Pr }}} \text {. }
$$

where

$$
\begin{aligned}
28.988 \mathrm{C}_{\mathrm{p}} & =\text { latent heat of the product stream, } \mathrm{J} / \mathrm{mol}, \\
\eta_{\text {iso }} & =\text { isothermal efficiency of the expander, }
\end{aligned}
$$

and $\quad \mathrm{R}=$ gas constant.

The recoverable power from the isothermal expander is equal to

$$
W_{R_{\text {iso }}}=28.988\left(C_{p}\right)(\dot{\omega}) \text {. }
$$

An equation for the overall cycle efficiency can now be written by substituting into the general cycle efficiency expression, equation (1.2.2).

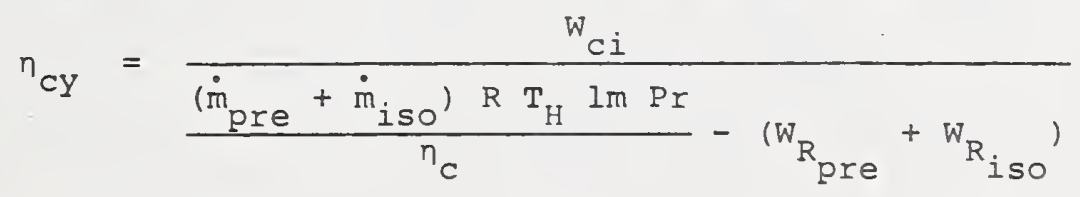


where

$W_{c i}=$ minimum ideal-cycle power, equation $(1.2 .8)$
$\dot{m}_{\text {pre }}=$ total mass flow through the precooling expanders, equations
$(1.2 .10)$ and 1.2 .16$)$

$\dot{\mathrm{m}}_{\text {iso }}=$ mass flow through the isothermal expander, equation $(1.2 .20)$ $\mathrm{W}_{\mathrm{R}_{\text {pre }}}=\quad \begin{aligned} & \text { recoverable work from the precooling expanders, equation } \\ & (1.2 .19)\end{aligned}$

and ${ }_{R_{\text {iso }}}=\begin{aligned} & \text { recoverable work from the isothermal expander, equation } \\ & (1.2 .21) \text {. }\end{aligned}$

The specific heat $\left(C_{p}\right)$ cancels in equation 1.2 .22 when the results of the previous equations are substituted. This leaves the condensing temperature $\left(T_{C}\right)$, the ratio of latent heat to specific heat, and the ratio of specifc heats $(k)$ as the only parameters relating the equation to a hydrogen liquefier. Although the specific heat ratio, $k$, varies over a broad range as the temperature of hydrogen is reduced, it was found that this variation affected the optimum pressure ratio for the cycle but had little effect on the maximum cycle efficiency shown in the results. The ratio of latent heat to specific heat $(28.988 \mathrm{~K})$ was determined for the case of equilibrium conversion from normal to parahydrogen as the temperature of the product stream is reduced. The effect of conversion at temperatures lower than equilibrium can be determined by varying the latent heat to specific heat ratio.

Cycle efficiencies as a function of expander and compressor efficiencies are shown on figure 1.2. In this figure the precooling expanders and the isothermal expander were assumed to have the same numerical efficiency. The plotted results are for a liquefier with six precooling expanders.

The results show that without considering any losses from heat exchanger temperature differences or pressure drop, the maximum cycle efficiency obtainable with 80 percent of adiabatic precooling expanders, an 80 percent isothermal expander, and a 60 percent isothermal compressor is approximately 40 percent of carnot.

\subsubsection{Losses due to heat exchanger temperature difference}

Calculation of the effect of heat exchanger temperature difference on overall liquefier efficiency greatly complicates the simple equation used in the previous section. This complication results because losses in the colder portion of the cycle compound the losses due to heat exchanger temperature differences in the warmer portion of the cycle. The cycle efficiency calculation must therefore become more specific about flow rates in each heat exchanger and through each expander. In the previous cycle efficiency calculation, the number of expanders could be non-integer without affecting the validity of the results. However, in considering the heat exchanger temperature differences losses, the number of expanders must be integer.

When heat exchanger temperature differences are considered, the number of precooling expanders required in the cycle is increased because of the overlaps between the discharge temperature of a previous expander and the inlet temperature of the following expander. Also, the flow through each expander must be higher than the product stream flow rate because the temperature difference in each heat exchanger decreases with absolute temperature.

The procedure followed was to select a number of precooling expanders, solve for the required pressure ratio and determine the flow through the isothermal expander. Using this flow as the inlet and discharge flow to the bottom or coldest portion of the $n$th heat exchanger (figure 1.1), the required flow to the top or warm end of the same heat exchanger was determined from an 


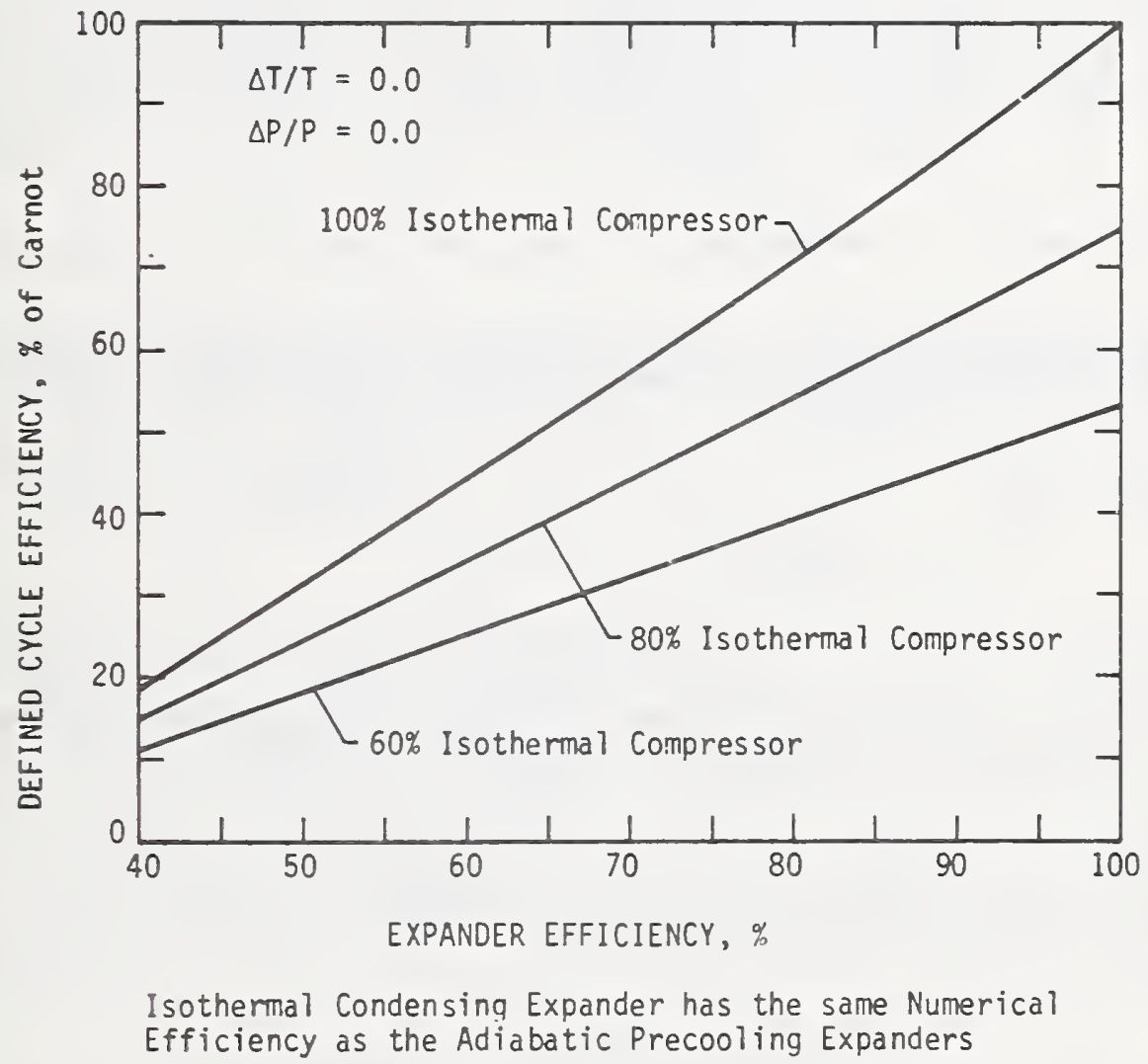

Figure 1.2. Defined cycle efficiency without pressure drop and heat exchanger temperature difference losses. 
energy balance around the heat exchanger. The product flow stream maintains its flow of $\omega$ throughout the procedure. The flow at the top of the $n$th heat exchanger now becomes the inlet and discharge flow for the cold end of the $(n-1)$ heat exchanger. The summing procedure continues to the compressor end of the cycle when the total compressor flow is determined.

The pressure ratio determination is made by deriving an equation similar to equation (1.2.15) except that $C$ (where $C=\Delta T / T$, used to define heat exchange temperature difference) is included in the derivation. Equation $(1.2 .15)$ now becomes

$$
\begin{aligned}
& T_{C}=T_{H}\left[1-\eta_{\text {pre }}+n_{\text {pre }} \operatorname{Pr}^{-\alpha /(1-C)]^{N} \text { exp, and }}\right. \\
& P_{r}=\left[\frac{n_{\text {pre }}}{\left.\frac{1}{N_{e x p}}+n_{\text {pre }}-1\right]}\right]^{\frac{1}{\alpha}} \text {. }
\end{aligned}
$$

By selecting the number of expanders, a required pressure ratio can be calculated.

Performing an energy balance around each heat exchanger, the following equations were derived and used to calculate the overall cycle efficiency.

$$
\text { 1. } \dot{\mathrm{m}}=\dot{\mathrm{m}}_{\text {iso }}+\dot{\mathrm{m}}_{\mathrm{pre}}=\sum_{n=N_{\exp }}^{n=1} \dot{m}_{n}=\sum_{n=N_{\text {exp }}}^{n=1} \frac{\dot{\omega}+m_{n+1}}{1-\mathrm{C}}
$$

where

$$
\begin{array}{ll}
\dot{\mathrm{m}} & =\text { the total mass flow through the expanders } \\
\dot{\mathrm{m}}_{\mathrm{N}} & =\text { mass flow through the isothermal expander or }
\end{array}
$$

2. $W_{E}=W_{R_{\text {pre }}}+W_{R_{\text {iso }}}=w_{R_{\text {iso }}}+\sum_{n=N}^{n=1}\left(\dot{m}_{n}-\dot{m}_{n+1}\right) C_{p}\left[T_{n}-T_{n+1}(1-C)\right]$

where

$$
\begin{array}{lll}
\mathrm{W}_{\mathrm{E}} & =\text { total recoverable expander power, } \\
{ }^{\mathrm{T}_{\mathrm{N}}} & =\mathrm{T}_{\mathrm{C} p+1} \\
\mathrm{~W}_{\mathrm{R}} & =\begin{array}{l}
\text { recoverable power from the isothermal expander } \\
\text { equation }(1.2 .21) .
\end{array} \\
\mathrm{W}_{\mathrm{R}} & =\text { recoverable power from the precooling expanders, }
\end{array}
$$

and

$$
\left.T_{n}=T_{n+1} /\left[1-n_{p r e}+n_{p r e} \operatorname{Pr}{ }^{-\alpha}\right) /(1-C)\right] .
$$


3. $\eta_{C y}=\frac{W_{C i}}{\frac{\dot{m} R_{H} l n \operatorname{Pr}}{n_{C}}-W_{E}}$.

The results of the calculated cycle efficiency including losses due to heat exchanger temperature difference will be presented in the next section.

\subsubsection{Losses due to pressure drop}

The pressure drop losses were included in the cycle efficiency calculation in a rather inexact method. Since it was difficult to calculate the losses when the pressure drop was distributed throughout the system, cycle efficiencies were calculated with the entire pressure drop occurring at two locations. The minimum losses due to system pressure drop were calculated by taking the entire pressure drop immediately before and after the isothermal expander. The maximum loss was determined by taking the entire pressure drop immediately before and after the main compressor. In the calculations the reduced pressure ratio for either the isothermal expander or the entire cycle was found by:

$$
\operatorname{Pr}_{r}=\operatorname{Pr} \frac{(1-\Delta \mathrm{P} / \mathrm{P})}{(1+\Delta \mathrm{P} / \mathrm{P})} \text {. }
$$

Figures 1.3 and 1.4 show the final results of the cycle efficiency analysis. All losses are included in the plots with the double line denoting the maximum and minimum pressure drop effect. The cycle efficiency varied with the number of expanders and if the maximum efficiency occurred with less than six expanders that point was plotted, otherwise the cycle efficiency for six precooling expanders was plotted.

\subsubsection{Multipressure liquefaction cycles}

Losses in the cold end of the liquefaction cycle increase the flow in the warm end of the cycle. This increased warm end flow results in increased warm end losses. To minimize these losses, a three pressure cycle (employed in most state-of-the-art hydrogen liquefiers) can be simulated with the defined cycle by increasing the pressure ratio across the isothermal expander while maintaining the pressure ratio across the precooling expanders. Although the three pressure cycle requires an additional compressor and more complex heat exchangers, an increase in the cycle efficiency of one to two percentage points can be attained as shown by figure 1.5. The results shown on figure 1.5 are for a fixed pressure ratio of 9.6 across the precooling expander while the pressure ratio across the isothermal expander was varied from 9.6 to 100.

\subsection{The Real Hydrogen Liquefier}

A more practical liquefier has many similarities to the defined cycle but real properties of hydrogen must be used instead of the ideal fluid equations. Hydrogen with variable specific heats and a positive Joule-Thomson coefficient at low temperatures introduces many variables not considered in the defined cycle study. Whereas the defined cycle was limited to the use of an isothermal expander, the real cycle allowed the use of either a JouleThomson valve, a wet expander (which contains liquid in its discharge), or an expansion ejector as the final expansion device in the Iiquefier. The variable specific heats and the heat of converting normal to parahydrogen introduce the possibility of heat exchanger temperature pinches.

Computing the efficiency of many different optimized hydrogen Iiquefier cycles using the properties of hydrogen, shows that the majority of the hydrogen liquefier losses are due to the inefficiencies of the compressors and expanders. In comparison the remaining losses are so small that only 


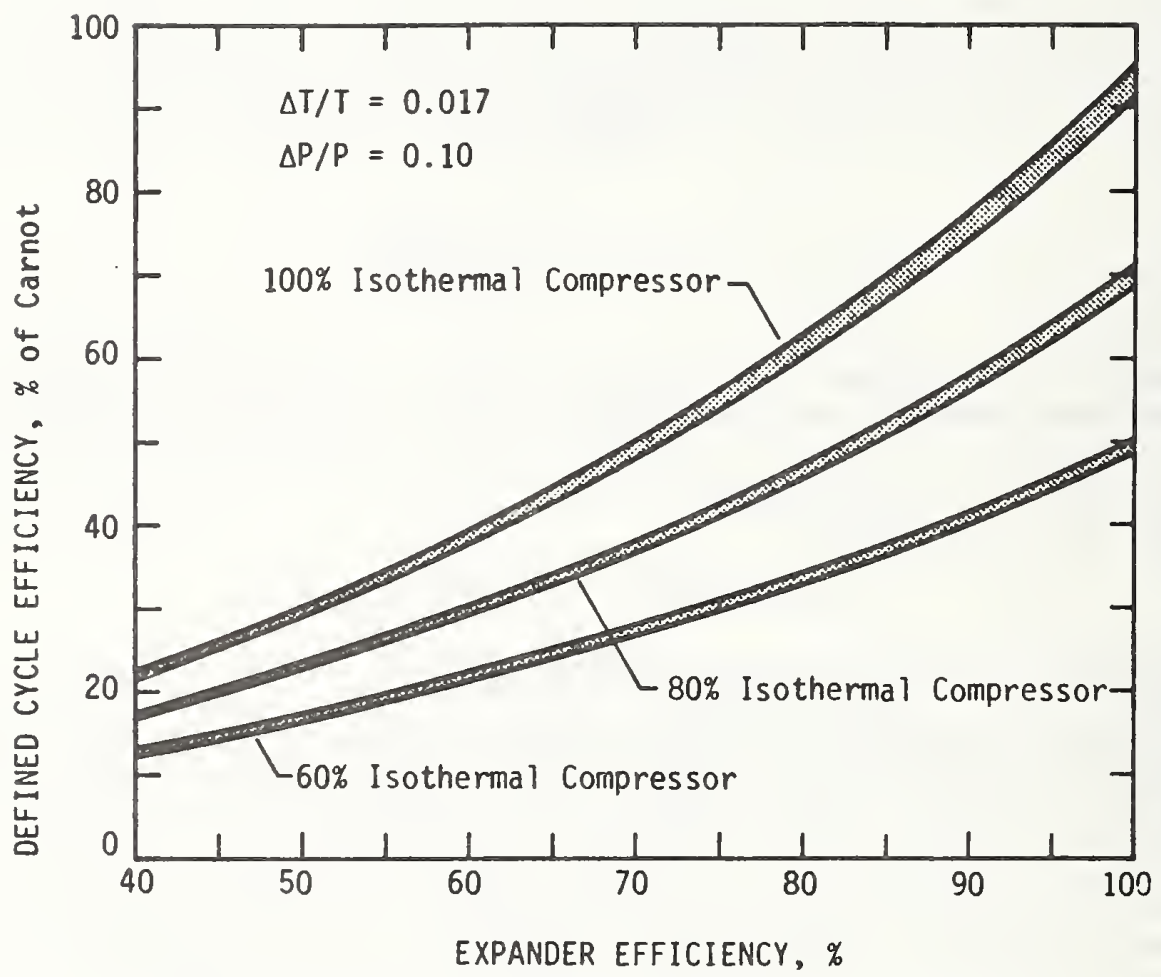

Isothermal Condensing Expander has the same Numerical Efficiency as the Adiabatic Precooling Expanders

Figure 1.3. Defined cycle efficiency including losses from pressure drop and heat exchanger temperature differences. 


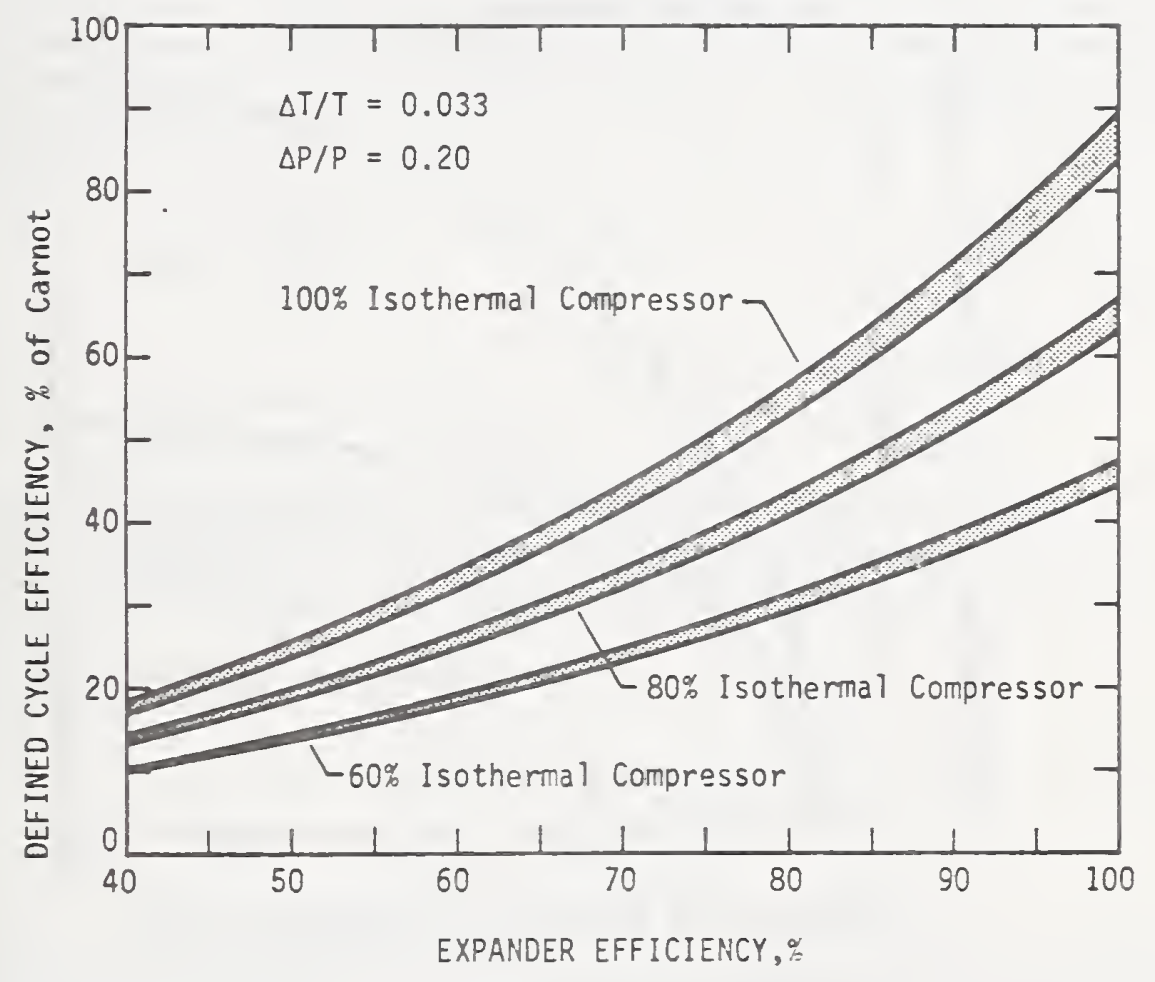

Isothemal Condensing Expander has the same Humerical Efficiency as the Adiabatic Precooling Expanders

Figure 1.4. Defined cycle efficiency including losses from pressure drop and heat exchanger temperature differences. 


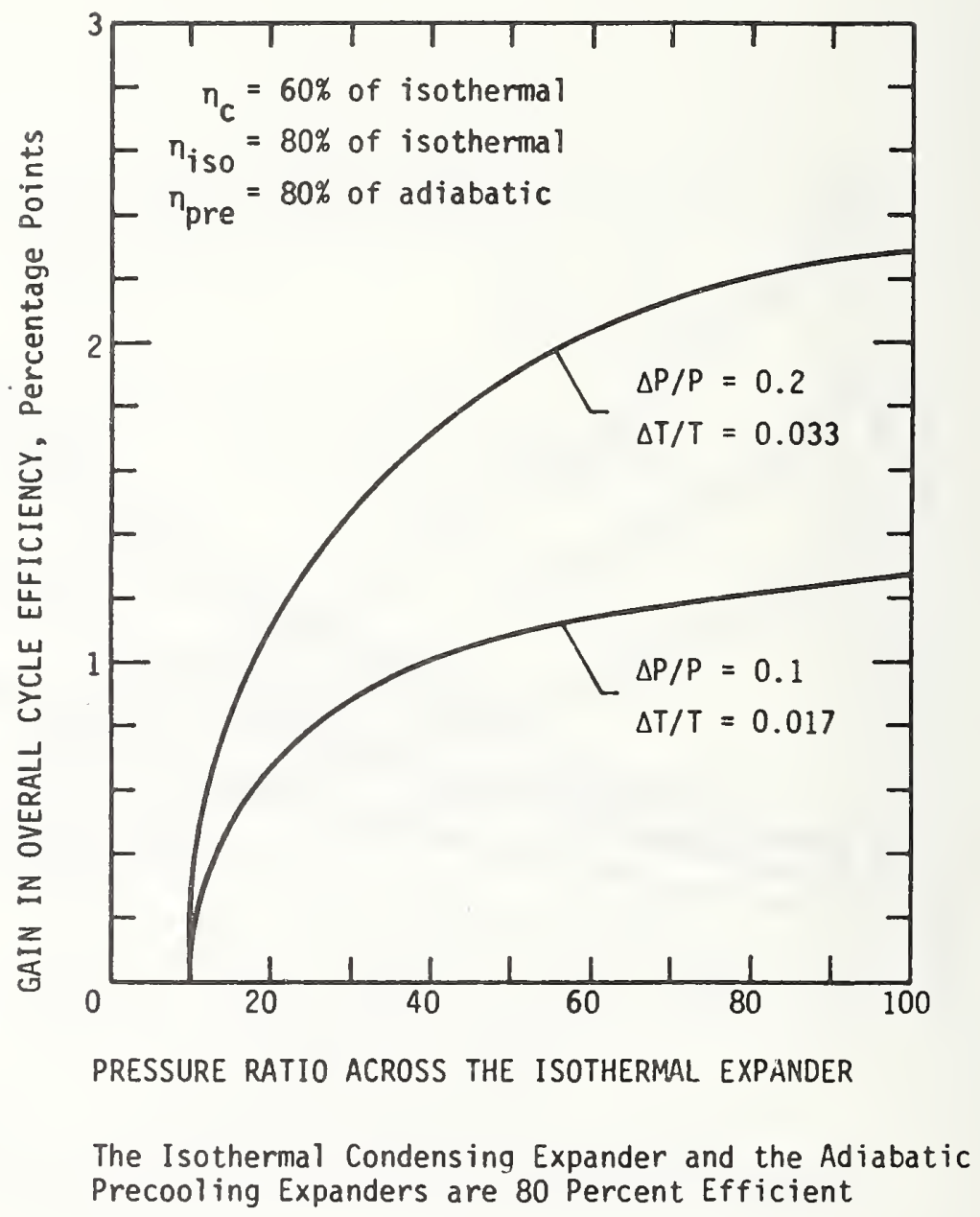

Figure 1.5. Increase in defined cycle efficiency resulting from the use of a three pressure cycle. 
slight gains in liquefier efficiency can be achieved by using unreasonably large heat exchangers, and/or by substituting the more thermodynamically efficient expansion ejector or wet expander for the Joule-Thomson expansion valve as the final expansion device. Maximum liquefier efficiency is achieved by removing the heat of converting normal hydrogen to parahydrogen at the highest temperature possible and by locating the expanders to minimize heat exchanger temperature differences. Choosing between a Claude cycle, Brayton cycle, or cascade cycle is primarily a matter of providing the best pressure ratios and inlet temperatures for the available compressors and expanders rather than a matter of changing the hydrogen liquefier efficiency.

\subsubsection{Efficiency and losses of real liquefier components}

Efficiency is defined as the ratio of ideal work to actual work for a particular process. Losses for all components were determined using an availability balance around the component. The sum of the losses and the ideal power required to produce a unit of liquid divided by the isothermal compressor efficiency minus the power output of the expanders resulted in the actual power required to produce the liquid. Expressed in equation form the actual power required to produce the liquid is

$$
P_{a}=\frac{L_{T}+W_{C i}}{n_{C}}-W_{E^{\prime}}
$$

where

$\begin{aligned} \mathrm{P}_{\mathrm{a}} & =\text { actual power required to produce liquid, } \\ \mathrm{I}_{\mathrm{T}} & =\text { total liquefier losses, } \\ { }^{\mathrm{W}_{\mathrm{C}}} & =\text { ideal power required to produce liquid, } \\ { }_{\mathrm{C}} & =\text { isothermal efficiency of the compressor, } \\ \text { and }{ }_{\mathrm{W}} & =\text { recoverable power from the expanders. }\end{aligned}$

Overall liquefier efficiency becomes,

$$
\eta=\frac{W_{C i}}{P_{a}}=\frac{{ }_{C i}}{\frac{L_{T}+W_{C i}}{n_{C}}-W_{E}} .
$$

The liquefier is 100 percent efficient when the efficiency of the compressor is 100 percent of isothermal, and the total losses in the liquefier are equal to the expander output power. In this equation (equation 1.3.2) the expander output power is treated as a loss because the room temperature compressor must be large enough to supply the total expander output power plus the ideal power required to produce the liquid.

In the following sections the methods used to calculate the losses for the various liquefier components are defined. Also, the state-of-the-art efficiencies are assigned to the components used in the practical liquefier.

\subsubsection{Compressor}

For a real gas, the ideal power required to compress a fluid is;

$$
P_{c i}=\dot{m}\left(\psi_{\text {out }}-\psi_{i n}\right) \text {, }
$$


where

and

$$
\begin{aligned}
& \mathrm{P}_{\mathrm{Ci}}=\text { isothermal compressor power, } \\
& \dot{\mathrm{m}}=\text { mass flow rate, } \\
& \psi_{\text {out }}=\text { availability of the outlet fluid, } \\
& \psi_{\text {in }}=\text { availability of the inlet fluid. }
\end{aligned}
$$

The compressor efficiency is then defined as;

$$
n_{c}=\frac{P_{c i}}{P_{a c}} \text {, where }
$$

$\mathrm{P}_{\mathrm{ac}}$ is the actual compressor power required by the liquefier. Compressor losses are determined bv:

$$
L_{c}=\dot{m}\left[\frac{1-n_{c}}{n_{c}}\left(\psi_{\text {out }}-\psi_{\text {in }}\right)\right]
$$

where

and

$$
\begin{aligned}
& \mathrm{L}_{\mathrm{C}}=\text { compressor losses, } \\
& n_{\mathrm{C}}=\text { isothermal compressor efficiency. }
\end{aligned}
$$

Compressor efficiencies are usually given in terms of the adiabatic work. Depending on the compression ratio, the isothermal efficiency of most compressors is 60 percent while very large compressors may approach 70 percent[8]. A compressor efficiency of 60 percent of isothermal was used throughout this study.

\subsubsection{Expanders}

Expander efficiency is expressed by;

where

$$
n_{\text {pre }}=\frac{\Delta h_{a}}{\Delta h_{s}} \text {, }
$$

and $\Delta \mathrm{h}_{\mathrm{S}}=$ isentropic specific enthalpy change across the expander.

$$
\begin{aligned}
& \eta_{\text {pre }}=\text { isentropic expander efficiency, } \\
& \Delta \mathrm{h}_{\mathrm{a}}=\text { actual specific enthalpy change across the expander, }
\end{aligned}
$$

Expander losses are determined by the difference in availability across the expander or;

$$
L_{e}=\dot{m}\left(\psi_{\text {in }}-\psi_{\text {out }}\right)
$$

Although this expander loss includes the power output of the expander, it is appropriate because room temperature compression power is required to supply the energy (see equation (1.3.2) and its discussion). The expander power was recovered by reducing the actual isothermal compressor power by the total power from the expanders.

Expander efficiencies of 80 percent of isentropic were used for the majority of the calculations. Efficiencies of 60 and 100 percent were also used to determine the effect of expander efficiency on overall liquefier 
efficiency. The 80 percent efficiency is reasonable [5] if care is taken to match operating pressure ratios and inlet temperatures to the characteristics of the expander.

\subsubsection{Joule-Thomson expansion valve}

The Joule-Thomson (JT) expansion valve has an efficiency equivalent to a zero expander efficiency. Ignoring minor velocity effects, the zero efficiency results in no change in enthalpy across the valve during an expansion process.

The Joule-Thomson valve losses tend to be high because of the zero efficiency; however, they can be minimized by carefully selecting the operating conditions. Losses are determined by;

$$
L_{J T}=\dot{m}\left(\psi_{\text {in }}-\psi_{\text {out }}\right) \text {. }
$$

\subsubsection{Expansion ejector valve}

The expansion ejector valve was originally proposed to produce refrigeration at temperatures below the normal boiling temperature of the refrigerant [5]. Instead of using room temperature vacuum pumps to reduce the pressure of the liquid bath, the expansion ejector uses some of the energy of the high pressure, cold gas refrigerant to pump a second liquid bath to a lower pressure. Figure 1.6 shows an expansion ejector and its location in the cold end of a liquefier.

The expansion ejector efficiency is given by;

$$
\eta_{e j}=\frac{\dot{m}_{2} \Delta h_{s} 3,2}{\dot{m}_{1} \Delta h_{s} 1,3} \text {, }
$$

where

$$
\begin{aligned}
& \dot{\mathrm{m}}=\text { mass flow, } \\
& \Delta \mathrm{h}_{\mathrm{s}}=\text { isentropic specific enthalpy change, }
\end{aligned}
$$

subscripts

and

1 = primary supply stream,

2 = secondary or pumped stream,

3 = discharge stream.

by;

Expansion ejector losses are determined from the availability functions

$$
L_{e j}=\dot{m}_{1} \psi_{1}+\dot{m}_{2} \psi_{2}-\left(\dot{m}_{1}+\dot{m}_{2}\right) \psi_{3} \cdot
$$

Expansion ejector efficiencies have not been measured using hyarogen; however, they have been rieasured using nitrogen [6]. Since the primary and secondary flows are the same gas, the ejector efficiency should be nearly the same using hydrogen or nitrogen. The efficiencies reported in the nitrogen experiment are a function of the primary to secondary mass flow ratio, and they range from zero to nearly 20 percent. The efficiencies used in the hydrogen liquefier calculations were varied accordingly. 


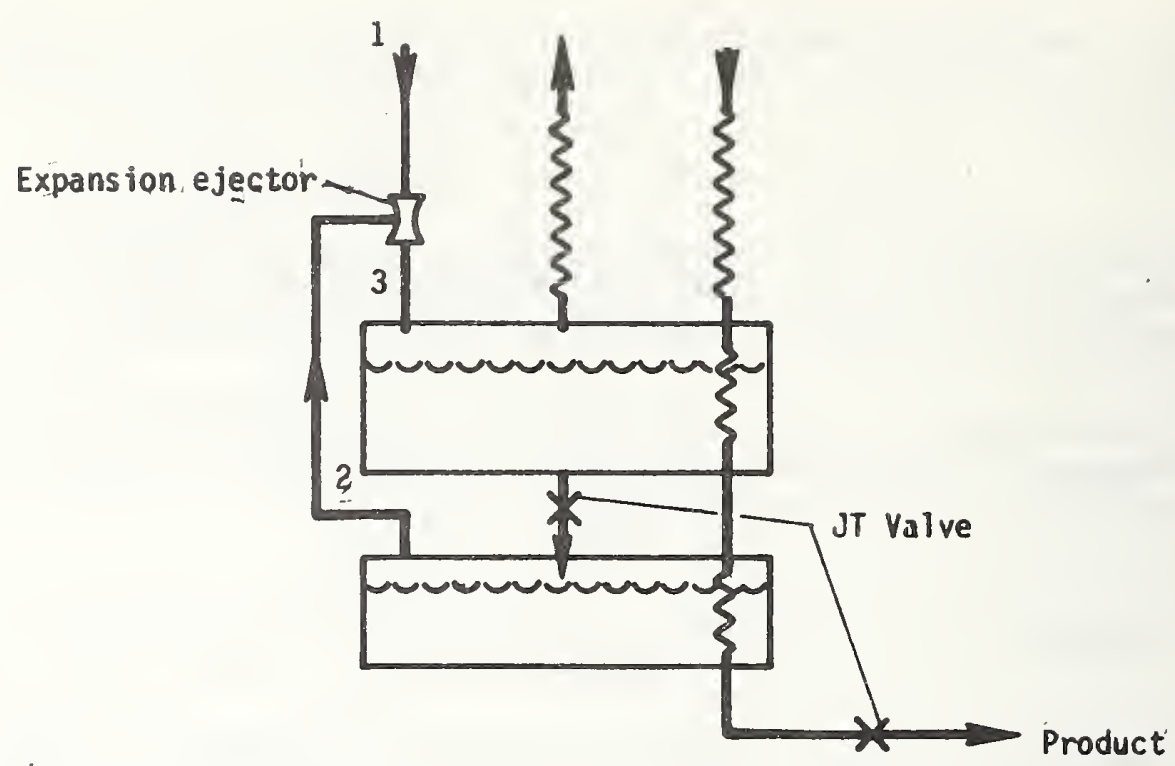

COLD END WITH AN EXPANSION EJECTOR

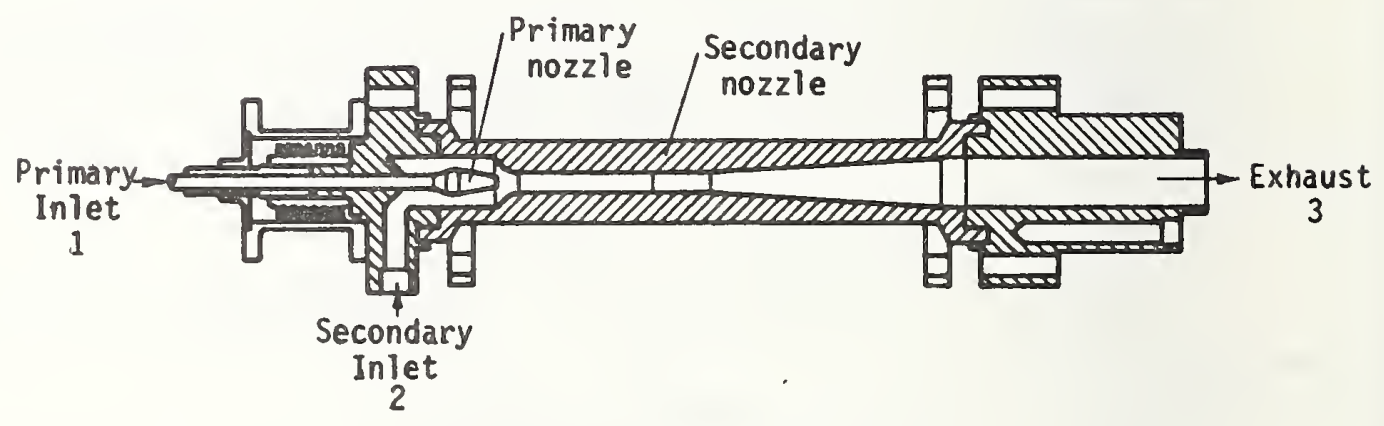

EXPANSION EJECTOR

Figure 1.6. An expansion ejector and a cold end using the ejector. 
Selecting the proper counterflow heat exchanger involves a balance between the cost of energy to produce the liquid and the capital cost of the exchanger. Decreasing the heat exchanger temperature difference improves the liquefier efficiency but may result in a large and overly expensive exchanger. Thus, the size of each exchanger was calculated based on assigned end point temperatures. If any heat exchanger in the liquefier was unreasonably small or large, the end point temperatures were reassigned and the liquefier efficiency recalculated.

Heat exchanger size was determined using a method described by Daney [7]. He based the heat exchanger size on the numerical value of $\mathrm{AU} / \mathrm{m}$ found from;

$$
\frac{\mathrm{AU}}{\mathrm{n}}=\frac{\mathrm{dh}}{\left(\Delta \mathrm{T}_{\mathrm{L}}\right) \mathrm{d} \alpha} \text {, }
$$

where

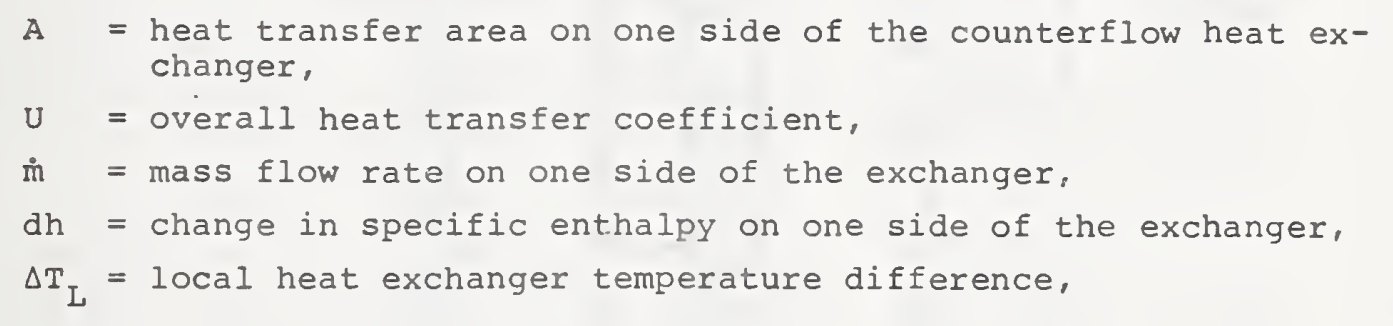

and

$$
\mathrm{d} \alpha=\mathrm{dA} / \mathrm{A} \text {. }
$$

The local heat exchanger temperature differences for 20 points along the length of the exchanger were used to numerically integrate the right side of the above equation.

The heat exchanger size was varied from 300 to $1000 \mathrm{~J} /(\mathrm{mol} \mathrm{K}$ ) in the study. These sizes provided a good balance between the capital cost and losses for the heat exchangers.

\subsubsection{Real hydrogen liquefier cycle}

A schematic for a representative hydrogen liquefier is shown in figure 1.7 and the corresponding fluid states are given in table 1.1. Many other combinations and numbers of Claude and Brayton modules were investigated, but this liquefier (with six precooling expanders in Claude modules and a Joule-Thomson (JT) valve as the final expansion device) is taken as typical. The fluid states shown in table 1.1 show the heat exchanger temperature differences and pressure drops. The product stream $(4,8,12$, etc.) is at a sufficient pressure to condense in the normal hydrogen liquid bath and it is maintained at equilibrium ortho-para concentration as it is cooled. The primary JT expansion valve is supplied by a separate compressor with the pressure and temperature at point 25 adjusted for maximum liquefier efficiency. The refrigerant supply pressure (point 2) is selected to eliminate the intermediate heat exchangers between the modules, i.e. the inlet temperature of a following expander is nearly the same as the discharge temperature of a preceding expander. Eliminating the intermediate heat exchangers increases liquefier efficiency since the temperature differences of the remaining exchangers are influenced less by unbalanced flows, variable specific heats, etc.

The precooler refrigerant is normal hydrogen (streams 1, 2 and 3) except for the small amount of parahydrogen mixed into the returning low pressure refrigerant (point 29). The increased parahydrogen content is accounted for in the precooler return flow but is converted back to normal hydrogen in the room temperature compressor. Because of the relatively low parahydrogen flow at point 32, the back conversion assumption has an insignificant effect on the overall liquefier efficiency. 


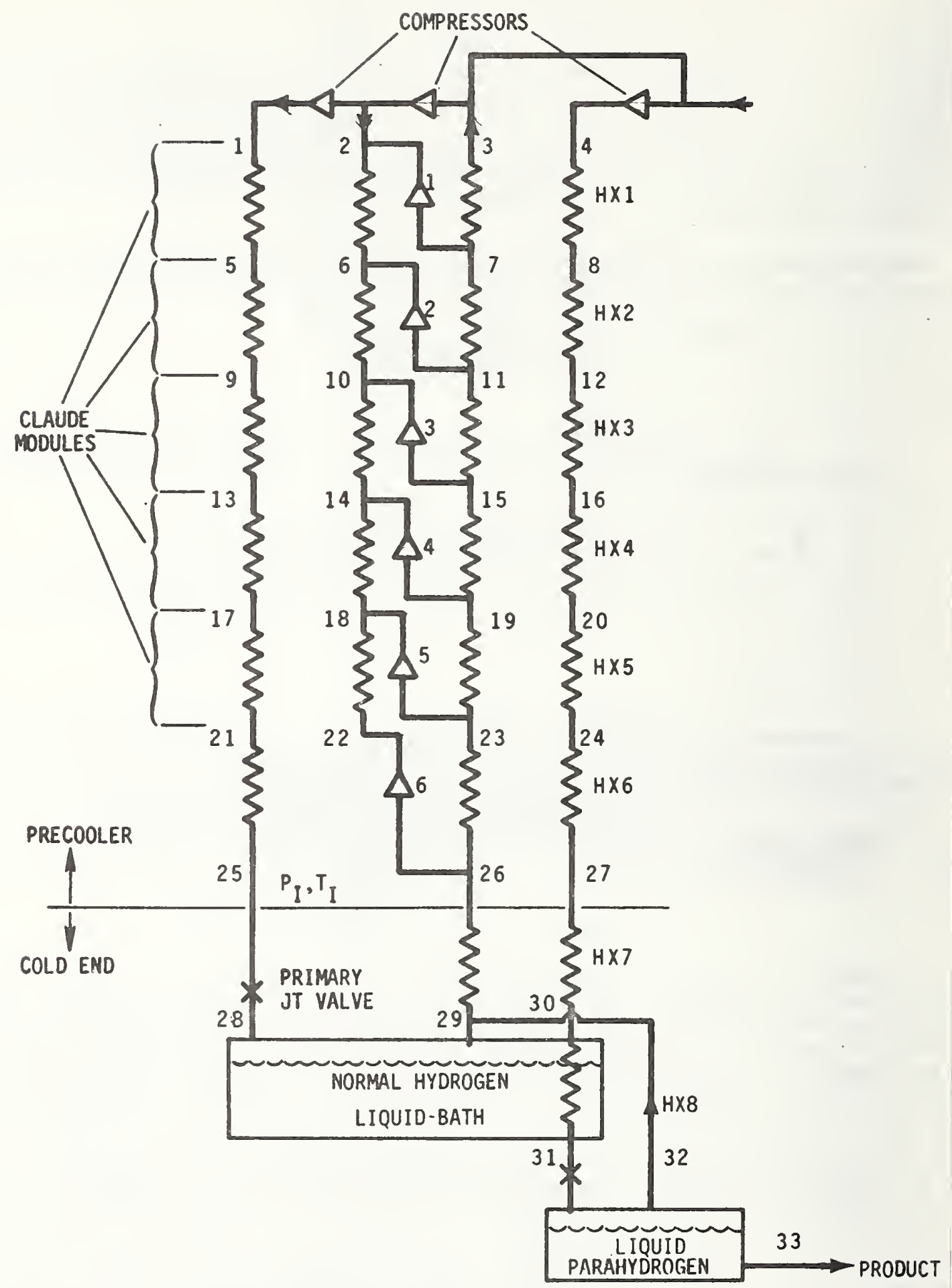

Figure 1.7. Representative hydrogen liquefier. 
Table 1.1 Fluid states for example hydrogen liquefier (figure 1.2).

\begin{tabular}{|c|c|c|c|c|c|c|c|}
\hline $\mathrm{PT}$ & atm & $\mathrm{T}$ & $\mathrm{J} /(\mathrm{g} \cdot \mathrm{mol})$ & $\mathrm{J} /(\mathrm{g} \cdot \mathrm{mol})$ & $\mathrm{J} /(\mathrm{g} \cdot \mathrm{mol} \cdot \mathrm{k})$ & 向 & $\begin{array}{c}\text { Para } \\
\text { Content } \\
\%\end{array}$ \\
\hline 1 & 15.923 & 300 & 8534.483 & 119.2315 & 6926.237 & 1.0 & 25 \\
\hline 2 & 6.171 & 300 & 8525.816 & 127.1327 & 4547.207 & 10.2954 & 25 \\
\hline 3 & 1.130 & 294.985 & 8521.895 & 140.7698 & 306.964 & 11.3205 & 25.16 \\
\hline 4 & 1.740 & 300 & 8521.895 & 137.667 & 1383.097 & .9107 & 25 \\
\hline 5 & 15.765 & 209.603 & 5961.912 & 109.126 & 7385.382 & 1.0 & 25 \\
\hline 6 & 6.109 & 209.603 & 5960.620 & 117.057 & 5004.652 & 9.1791 & 25 \\
\hline 7 & 1.142 & 206.099 & 5863.111 & 130.561 & 855.996 & 10.2040 & 25.18 \\
\hline 8 & 1.723 & 209.603 & 5957.341 & 127.591 & 1841.142 & .9107 & equil. \\
\hline 9 & 15.609 & 143.360 & 4190.847 & 99.077 & 8628.977 & 1.0 & 25 \\
\hline 10 & 6.048 & 143.360 & 4201.616 & 107.079 & 6238.929 & 6.7339 & 25 \\
\hline 11 & 1.153 & 140.964 & 4145.566 & 120.493 & 2158.972 & 9.0545 & $25.2 i$ \\
\hline 12 & 1.706 & 143.360 & 4166.843 & 117.419 & 3102.158 & .9107 & equil. \\
\hline 13 & 15.455 & 94.272 & 2993.868 & 88.973 & 10463.103 & 1.0 & 25 \\
\hline 14 & 5.988 & 94.272 & 3025.948 & 97.165 & 8037.805 & 6.7339 & 25 \\
\hline 15 & 1.165 & 92.696 & 3004.547 & 110.542 & 4003.066 & 7.7588 & 25.24 \\
\hline 16 & 1.689 & 94.272 & 2829.978 & 106.051 & 5175.835 & .9107 & equil. \\
\hline 17 & 15.302 & 59.686 & 2183.928 & 78.335 & 12844.752 & 1.0 & 25 \\
\hline 18 & 5.928 & 59.686 & 2258.297 & 87.112 & 10285.832 & 5.0460 & 25 \\
\hline 19 & 1.176 & 58.688 & 2269.863 & 100.611 & 6247.654 & 6.0709 & 25.31 \\
\hline 20 & 1.672 & 59.686 & 1713.571 & 91.243 & 8501.981 & .9107 & equil. \\
\hline 21 & 15.150 & 38.352 & 1565.074 & 65.318 & 16130.801 & 1.0 & 25 \\
\hline 22 & 5.869 & 38.352 & 1767.462 & 76.972 & 12838.948 & 3.0932 & 25 \\
\hline 23 & 1.188 & 36.525 & 1797.070 & 90.437 & 8827.278 & 4.1181 & 25.45 \\
\hline 24 & 1.656 & 38.352 & 908.545 & 74.647 & 12675.599 & .9107 & equil. \\
\hline 25 & 15.0 & 24.066 & 651.222 & 37.344 & 23609.245 & 1.0 & 25 \\
\hline 26 & 1.2 & 22.970 & 1476.127 & 79.753 & 11711.305 & 1.0248 & 26.82 \\
\hline 27 & 1.639 & 24.066 & 460.745 & 60.265 & 16542.322 & .9107 & equil. \\
\hline 28 & 1.212 & 20.944 & 651.222 & 39.455 & 22975.845 & 1.0 & 25 \\
\hline 29 & 1.212 & 20.944 & 1451.586 & 77.671 & 12311.629 & 1.0 & 25 \\
\hline 30 & 1.623 & 22.030 & 404.123 & 57.881 & 17201.106 & .9107 & equil. \\
\hline 31 & 1.607 & 21.991 & -474.703 & 17.992 & 28288.859 & .9107 & equil. \\
\hline 32 & 1.212 & 20.962 & 389.344 & 59.313 & 16756.521 & .0248 & 100 \\
\hline 33 & 1.218 & 20.962 & -498.958 & 16.918 & 28586.829 & .8858 & 100 \\
\hline
\end{tabular}


The calculated compressor work per unit of product required to overcome the losses of other types of precoolers considered is shown on table 1.2. This compressor work is a function of tine temperature and pressure at the interface between the precooler and the cold end ( $P_{I}$ ' $T{ }^{\prime}$ ' point 25, figure 1.7), the number and efficiency of the expanders, the pressure drop and size of the heat exchangers and the ratio of the refrigerant stream mass flow to the product stream mass flow $\left(\dot{m}_{3} / \stackrel{m}{m}_{4}\right.$, figure 1.7). The compressor work,

shown per gm mole of product stream flow (point 27), is based on a compressor efficiency of 60 percent of isothermal and the recovery of the total expander output. The pressure of the returning refrigerant (pt 3, figure 1.7) was 1.0 atm for all precoolers considered. Each precooler was assembled from Brayton and Claude modules as designated by the cycle type shown on table 1.2 where the warmest module is listed first proceeding to the coldest module listed last. The claude modules were always used without the intermediate heat exchanger as explained previously. Figure 1.8 is a plot of compressor work required to overcome losses in the precooler versus the interface temperature between the precooler and cold end.

Similar plots of compressor work to overcome losses in the JT expansion valve, the expansion ejector, and the wet expander cold ends are shown on figures 1.9 and 1.10. The compressor work shown was minimized by choosing the optimum interface pressure for each cold end and each interface temperature and it is again expressed as the work per gram mole of product stream flow. Figure 1.9 shows a performance band for the expansion ejector cold end. The band is bounded by a zero efficiency curve (also used to define the performance of the JT valve cold end), and a 20 percent efficiency curve. Two performance curves are also shown for the wet expander cold end (figure 1.10). One curve is for a wet expander with 80 percent liquid in its exhaust, and the other curve is for a wet expander with the liquid in its exhaust limited to 24 percent by mass.

By using the performance information on figures $1.8,1.9$ and 1.10 , the optimum interface temperature and pressure can be found for the various cold ends. In order to find the overall liquefier efficiency using the various cold ends, an estimated precooler performance is defined by the hand-drawn curve on figure 1.8. The total work required by a liquefier can be found by summing the ideal work of liquefaction divided by the 60 percent isothermal compressor efficiency to the compressor work to overcome losses in the precooler (figure 1.8) and the chosen cold end (figure 1.9 and 1.10). In equation form this is

$$
w_{T}=w_{c i} / .6+w_{\text {pre }}+w_{C}
$$

where

and

$\mathrm{w}_{\mathrm{T}}=$ total liquefier work,
$\mathrm{w}_{\mathrm{Ci}}=$ ideal liquefier work,
$\mathrm{w}_{\mathrm{pre}}=$ compressor work to overcome losses in precooler,
$\mathrm{w}_{\mathrm{C}}=$ compressor work to overcome losses in cold end.

From the total work, the liquefier efficiency can be found and a plot of this liquefier efficiency versus interface temperature is shown on figure 1.11. The most efficient liquefier results when a wet expander with 80 percent liquid in its exhaust is used as the final expansion device. A reciprocating expander is able to operate at these conditions; however, a turbo-expander is limited to 24 percent or less liquid in its exhaust and the liquefier efficiency suffers. The expansion ejector requires a raised inlet temperature to recover any pumping power from the primary stream. At low inlet temperatures the expansion ejector becomes a JT valve with no pumping ability while at higher temperatures pumping energy is recovered from the primary stream. 
Table 1.2 Compressor work required to overcome losses for various types of precoolers.

\begin{tabular}{|c|c|c|c|c|c|c|c|c|c|c|c|c|c|}
\hline \multirow[t]{2}{*}{ Run } & \multirow{2}{*}{$\begin{array}{l}P_{I} \\
\text { atm }\end{array}$} & $\mathrm{T}_{I}$ & \multirow[t]{2}{*}{$\begin{array}{c}\text { No. } \\
\text { Exp's/Eff. }\end{array}$} & \multirow[t]{2}{*}{$\begin{array}{l}\text { Cycle } \\
\text { Type* }\end{array}$} & DPOP & 1 & $2^{\mathrm{HX}}$ & $\begin{array}{c}\text { Size } \\
3 \\
\end{array}$ & $\begin{array}{c}\text { Parame } \\
4 \\
\end{array}$ & 5 & 6 & \multirow[t]{2}{*}{$\begin{array}{l}\text { Ratio } \\
\dot{\text { m}}_{3} / \dot{\mathrm{x}}_{4}\end{array}$} & \multirow{2}{*}{$\begin{array}{l}\text { Comp. W } \\
\text { for Los } \\
\mathrm{J} /(\mathrm{g} \cdot \mathrm{mo}\end{array}$} \\
\hline & & $\mathrm{K}$ & & & \multicolumn{7}{|c|}{$\mathrm{J} /(\mathrm{g} \cdot \mathrm{mol} \cdot \mathrm{K})$} & & \\
\hline 1 & 30 & 34.03 & $6 / 80$ & $\mathrm{cccccc}$ & 0.01 & 511 & 513 & 532 & 617 & 394 & 157 & .7302 & 31774 \\
\hline 2 & 30 & 34 & $6 / 80$ & $\mathrm{cccccc}$ & 0.01 & 517 & 519 & 541 & 637 & 422 & 122 & .6578 & 31824 \\
\hline 6 & 25 & 30 & $4 / 80$ & $\mathrm{Cccc}$ & 0.01 & 668 & 482 & 437 & 225 & & & & 34209 \\
\hline 7 & 20 & 30.25 & $4 / 80$ & $\mathrm{CCCC}$ & 0.01 & 672 & 484 & 438 & 348 & & & .7769 & 34262 \\
\hline 8 & 10 & 32.5 & $6 / 80$ & $\mathrm{cccccc}$ & 0.01 & 587 & 585 & 607 & 690 & 572 & 89 & .2358 & 31187 \\
\hline 9 & 10 & 32.5 & $6 / 80$ & сссссC & 0.01 & 593 & 591 & 611 & 684 & 528 & 108 & .2436 & 33273 \\
\hline 11 & 15 & 30 & $6 / 80$ & $\mathrm{cccccc}$ & 0.01 & 563 & 560 & 572 & 622 & 354 & 380 & .6982 & 34362 \\
\hline 13 & 15 & 24 & $6 / 80$ & $\mathrm{cccccc}$ & 0.01 & 599 & 597 & 585 & 704 & 414 & 113 & .8858 & 35825 \\
\hline 20 & 30 & 34.1 & $6 / 80$ & $\mathrm{cccccc}$ & 0.01 & 510 & 512 & 531 & 615 & 392 & 158 & .7270 & 31360 \\
\hline 25 & 30 & 34 & $6 / 80$ & $\operatorname{cccccc}$ & 0.01 & 510 & 511 & 530 & 613 & 401 & 165 & .5889 & 33702 \\
\hline 26 & 30 & 34 & $6 / 80$ & $\mathrm{cccccc}$ & 0.01 & 510 & 511 & 529 & 612 & 399 & 163 & .5910 & 33684 \\
\hline 27 & 30 & 34 & $4 / 80$ & $\mathrm{CCCC}$ & 0.01 & 775 & 851 & 645 & 806 & & & .5889 & 31693 \\
\hline 28 & 30 & 34 & $4 / 80$ & $\mathrm{CcCC}$ & 0.01 & 775 & 857 & 646 & 805 & & & .5867 & 31712 \\
\hline 29 & 20 & 30.2 & $4 / 80$ & $\mathrm{BBBC}$ & 0.01 & 317 & 223 & 171 & 101 & & & .7769 & 35845 \\
\hline 32 & 7 & 35.3 & $4 / 80$ & BBBC & 0.01 & 680 & 587 & 441 & 627 & & & .2204 & 28859 \\
\hline 33 & 7 & 35.3 & $4 / 80$ & BBBC & 0.02 & 680 & 587 & 441 & 575 & & & .2173 & 32527 \\
\hline 34 & 5 & 36 & $4 / 80$ & BBBB & 0.01 & 615 & 522 & 382 & 297 & & & .1631 & 29001 \\
\hline 35 & 5 & 36 & $5 / 80$ & BBBBB & 0.01 & 586 & 524 & 421 & 324 & 277 & & .1631 & 27186 \\
\hline 36 & 5 & 36 & $6 / 80$ & BBBBBB & 0.01 & 561 & 516 & 442 & 355 & 289 & 263 & .1631 & 26291 \\
\hline 37 & 30 & 34 & $4 / 80$ & $\mathrm{Cccc}$ & 0.01 & 775 & 859 & 646 & 456 & & & .5359 & 30885 \\
\hline 38 & 30 & 34 & $4 / 60$ & $\mathrm{CCCC}$ & 0.01 & 686 & 621 & 716 & 538 & & & .5384 & 67707 \\
\hline 41 & 15 & 24 & $6 / 60$ & $\mathrm{cccccc}$ & 0.01 & 572 & 568 & 587 & 683 & 442 & 173 & .8858 & 71485 \\
\hline
\end{tabular}

* C designates a Claude module and a B designates a Brayton module. 


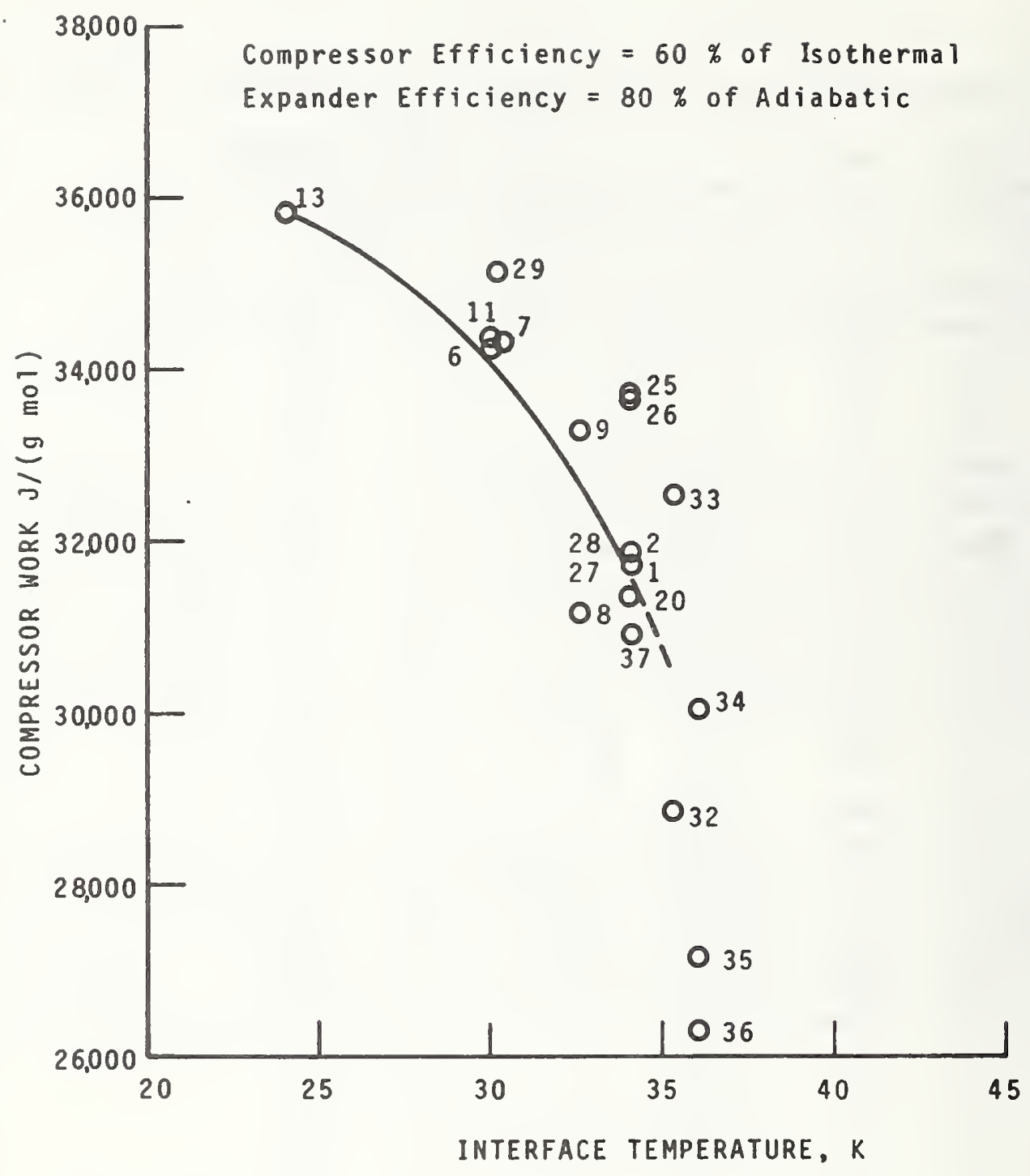

Figure 1.3. Compressor work required to overcome losses in the precooler for various cycles and interface temperatures. 


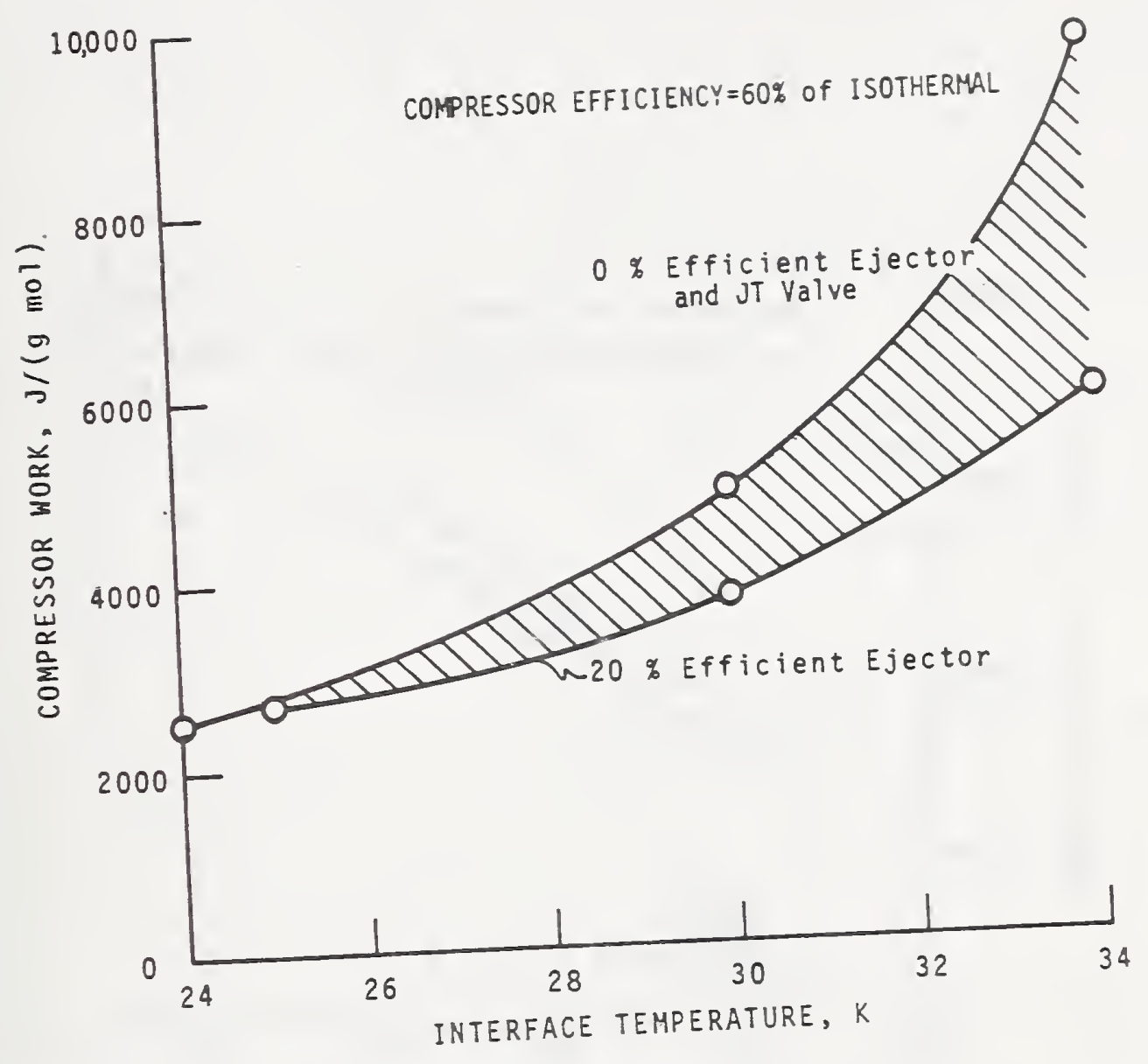

Compressor work required to overcome losses in the ejector Figure 1.9. Compressor work ralve cold end for various interface temperatures. 


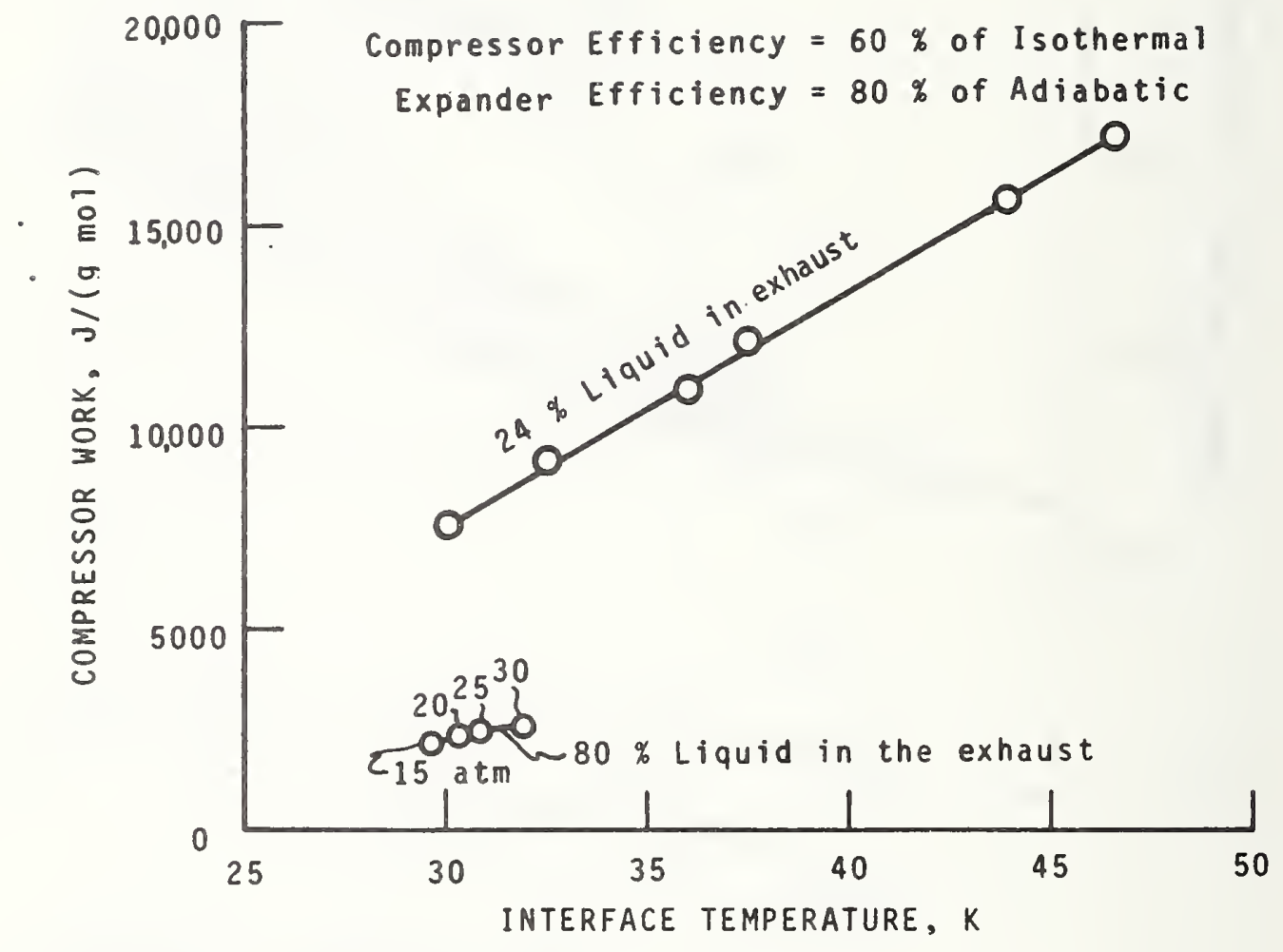

Figure 1.10. Compressor work required to overcome losses in a wet expander cold end for various interface temperatures. 


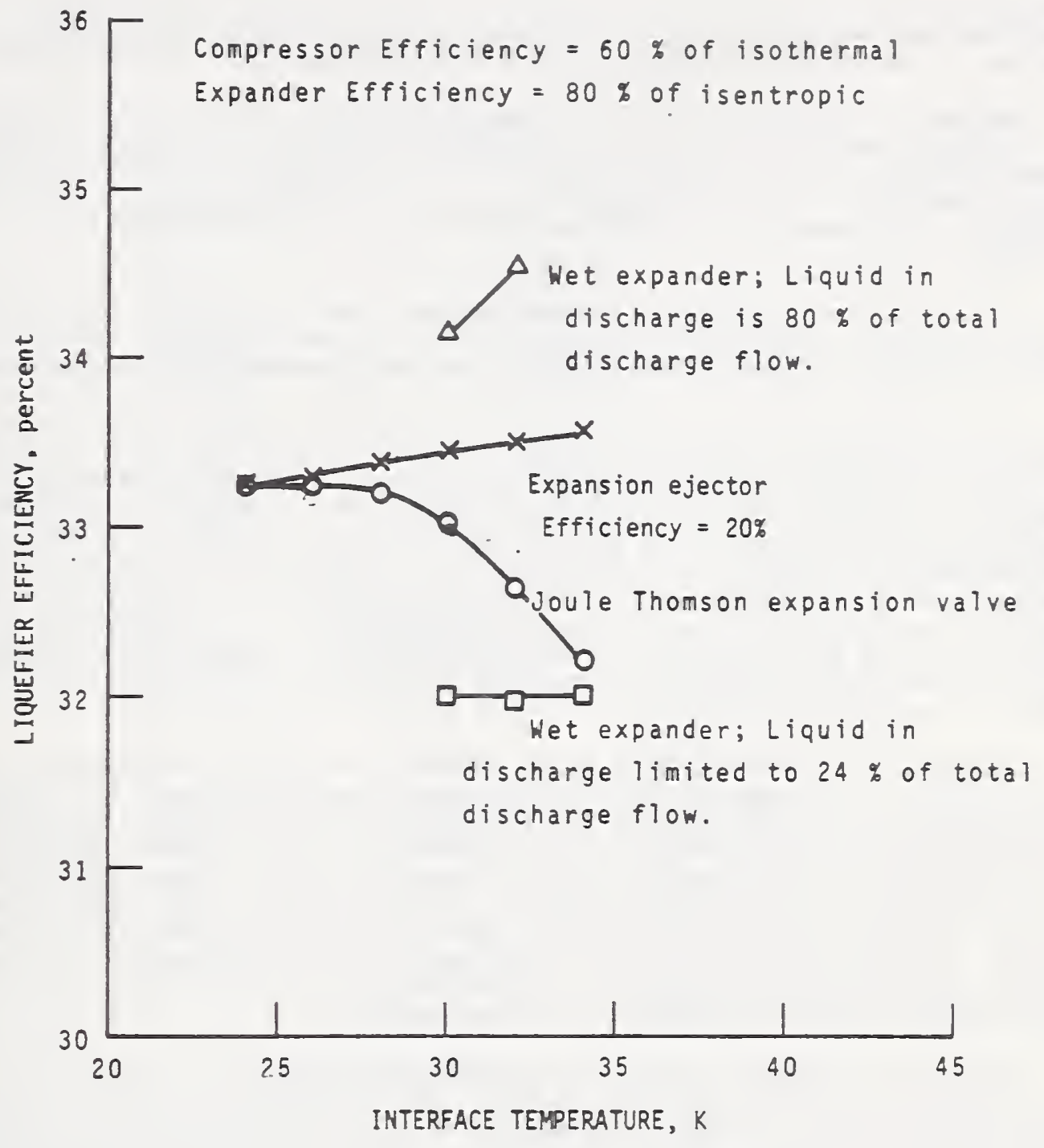

Figure 1.11. Hydrogen liquefier efficiency using a wet expander, expansion ejector or a Joule Thomson valve final expansion device versus the interface temperature. 
Because the losses in the cold end are a small percentage of the total liquefier losses, only a small advantage is gained by substituting a wet expander or expansion ejector for a JT valve in a properly optimized cycle.

Tables 1.3 and 1.4 show the losses for the representative liquefier. The liquefier efficiency is 33.24 percent of Carnot with the majority of the losses occurring in the compressors and expanders. The JT valve losses are low because its inlet temperature is low. Replacing the JT valve with a reversible expander would increase the liquefier efficiency to 33.72 percent of Carnot.

All liquefiers which were investigated used from four to six claude or Brayton modules in different combinations in the precooler and had nearly the same efficiency and loss distribution as the representative liquefier.

The choice of the type of precooler did not affect efficiency but it did change the precooler pressure ratio. Since an increased refrigeration load on a Brayton module is absorbed by increased expander pressure ratio, the compressor pressure ratio for the precooler of a liquefier employing mostly Brayton modules tended to be high. On the other hand, the claude module absorbs the refrigeration load by increased expander flow and the compressor pressure ratio is determined solely by the number of expanders (when the expanders are placed so the discharge temperature of a preceding expander is nearly the same as a following expander). Thus, the compressor pressure ratio for the precooler of a liquefier using six or more claude modules tended to be low.

Besides the Claude and Brayton modules, a separate nitrogen refrigerator can be used to precool the product stream (cascade cycle). A liquid nitrogen module using a JT valve as the final expansion device was compared to an all hydrogen Claude module precooling the same product stream. Figure 1.12 shows the schematics of the two modules. Identical losses above the inlet temperature of the two modules were assumed. The losses in the Joule-Thomson nitrogen module were determined and then the expander efficiency required to produce the same losses in the claude module was determined. If expander power is not recovered, the expander efficiency required to achieve identical losses between the two modules is 85.8 percent.

Figure 1.13 shows the room temperature compressor work required to cool the product stream for the two systems if the expander power is recovered. These results show that when expanders with efficiencies below about 75 percent are available, the best overall liquefier efficiency would be achieved with a cascade cycle. This conclusion must be qualified, however, because sufficient fluids are not available to provide the close precooling temperatures assumed in the example. This is especially true for temperatures below the normal boiling temperature of liquid nitrogen where expanders are required in the hydrogen liquefier to achieve high efficiencies. Other more practical reasons may suggest the use of liquid nitrogen precooling: 1) it may be possible to obtain higher efficiency expanders and compressors for nitrogen than hydrogen. Consequently, even though the warm temperature portions of the nitrogen precooling cycle are identical with an all-expander hydrogen cycle, lower losses will result from the higher component efficiencies; 2) liquid nitrogen may be required to purify the gaseous hydrogen supply. Since a nitrogen liquefier is required anyway, it can be increased in size to provide precooling to the hydrogen liquefier. Other than these two reasons, no particular gain in efficiency is provided by using liquid nitrogen precooling. 
Table 1.3 Individual component losses and turbine work for the representative liquefler.

\begin{tabular}{|c|c|c|c|c|}
\hline \multicolumn{5}{|c|}{ HEAT EXCHANGERS } \\
\hline \multirow[t]{2}{*}{ HX No. } & Size Parameter & \multicolumn{2}{|c|}{ Losses } & Total Losses \\
\hline & $J /(g \cdot m o l \cdot k)$ & \multicolumn{2}{|c|}{$\mathrm{J} /(\mathrm{g} \cdot \operatorname{mol} \cdot 1 \mathrm{iquid})$} & $\mathrm{J} /(\mathrm{g} \cdot \operatorname{mol} \cdot 1$ iquid $)$ \\
\hline 1 & 599.25 & \multicolumn{2}{|c|}{1286.628} & \\
\hline 2 & 597.61 & \multicolumn{2}{|c|}{1120.766} & \\
\hline 3 & 621.19 & \multicolumn{2}{|c|}{972.130} & \\
\hline 4 & 704.61 & \multicolumn{2}{|c|}{746.017} & \\
\hline 5 & $414 \cdot 12$ & \multicolumn{2}{|c|}{770.293} & \\
\hline 6 & 113.73 & \multicolumn{2}{|c|}{989.732} & \\
\hline 7 & 43.93 & \multicolumn{2}{|c|}{142.045} & \\
\hline \multirow[t]{2}{*}{ Totals } & & \multicolumn{2}{|c|}{6027.610} & 6027.610 \\
\hline & & \multicolumn{2}{|l|}{ EXPANDERS } & \\
\hline \multirow[t]{2}{*}{ Expander No. } & Efficiency & Hork Produced & Losses & \\
\hline & $\%$ & $J /(g \cdot \Sigma 01 \cdot 1$ iquid $)$ & $\mathrm{J} /(\mathrm{g} \cdot \mathrm{mol} \cdot 1$ iquid $)$ & \\
\hline 1 & 80 & 3355.308 & 4651.460 & \\
\hline 2 & 80 & 2355.252 & 3692.622 & \\
\hline 3 & 80 & 1750.861 & 3270.314 & \\
\hline 4 & 80 & 1440.650 & 3410.956 & \\
\hline 5 & 80 & 1016.764 & 3215.289 & \\
\hline 6 & 80 & 1017.328 & 3930.506 & \\
\hline \multirow[t]{2}{*}{ Totals } & & 10936.163 & 22171.147 & 22171.147 \\
\hline & & COLD END & & \\
\hline \multicolumn{2}{|c|}{ JT Valves } & \multicolumn{3}{|c|}{740.816} \\
\hline \multicolumn{2}{|c|}{ Other Cold End } & \multicolumn{3}{|c|}{640.107} \\
\hline \multirow[t]{2}{*}{ Totals } & & & 1380.923 & 1380.923 \\
\hline & & \multicolumn{2}{|c|}{ TOTAL LOSSES } & 29579.680 \\
\hline
\end{tabular}

Table 1.4 Work requirements for the representative liquefier.

\begin{tabular}{|c|c|c|}
\hline & $\begin{array}{l}\text { Hork Required } \\
(g \cdot m o l \cdot l \text { iquid })\end{array}$ & $\begin{array}{c}\text { Percent of } \\
\text { Total }\end{array}$ \\
\hline Compressor Losses ( 60 percent isothermal compressor) & 38777.673 & 45.09 \\
\hline Expander Losses ( 80 percent of isentropic efficiency) & 22171.147 & 25.78 \\
\hline Heat Exchanger Losses & 6027.610 & 7.01 \\
\hline Cold End Losses & 1380.923 & 1.60 \\
\hline Ideal Power Requirements & $\underline{28586.830}$ & $33.24^{1}$ \\
\hline Total & 96944.183 & 112.72 \\
\hline - Expander Power & -10936.163 & $-\underline{12.72}$ \\
\hline Total Liquefier Power Requirements & 86008.020 & 100.00 \\
\hline
\end{tabular}



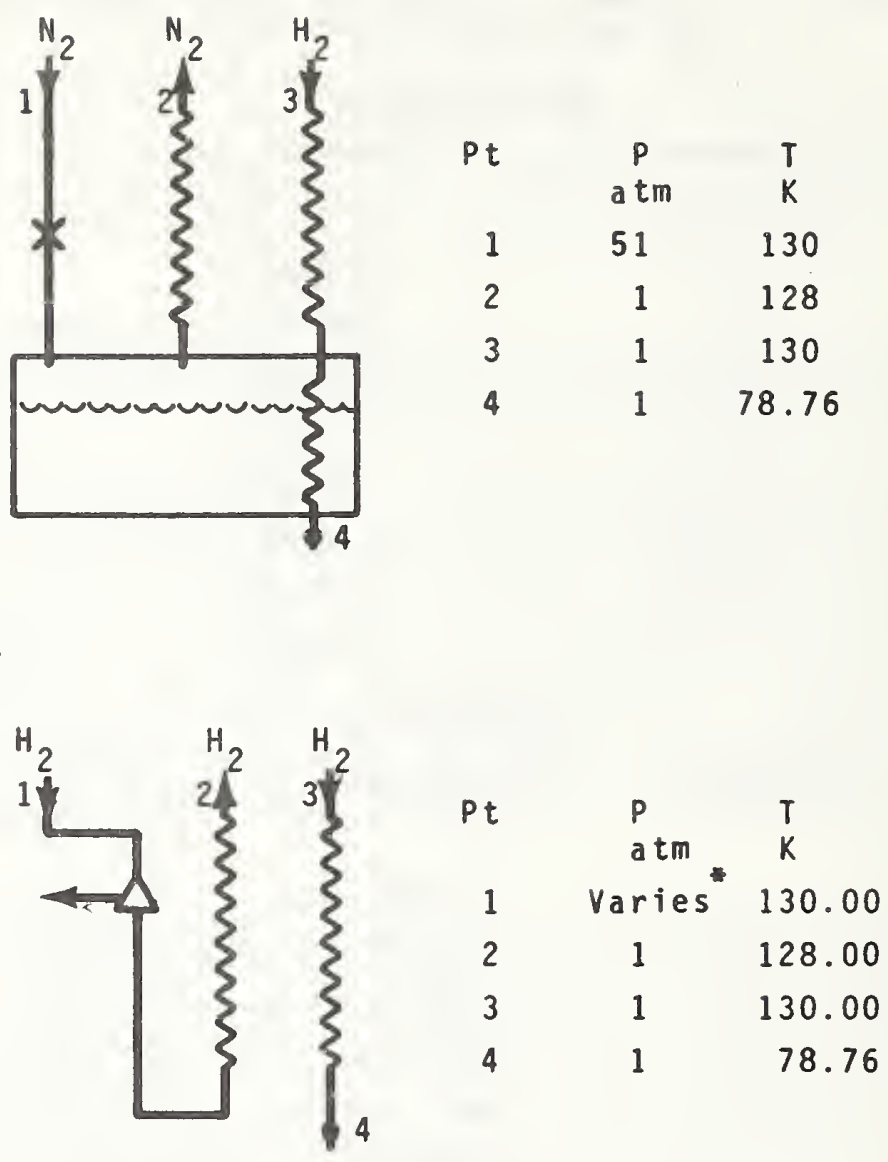

\footnotetext{
"Pressure at point 1 varies from 6.8 to 34 atm depending on the efficiency of the expander.
}

Figure 1.12. A nitrogen module with a JT valve and an all hydrogen Claude module cooling the same product stream. 


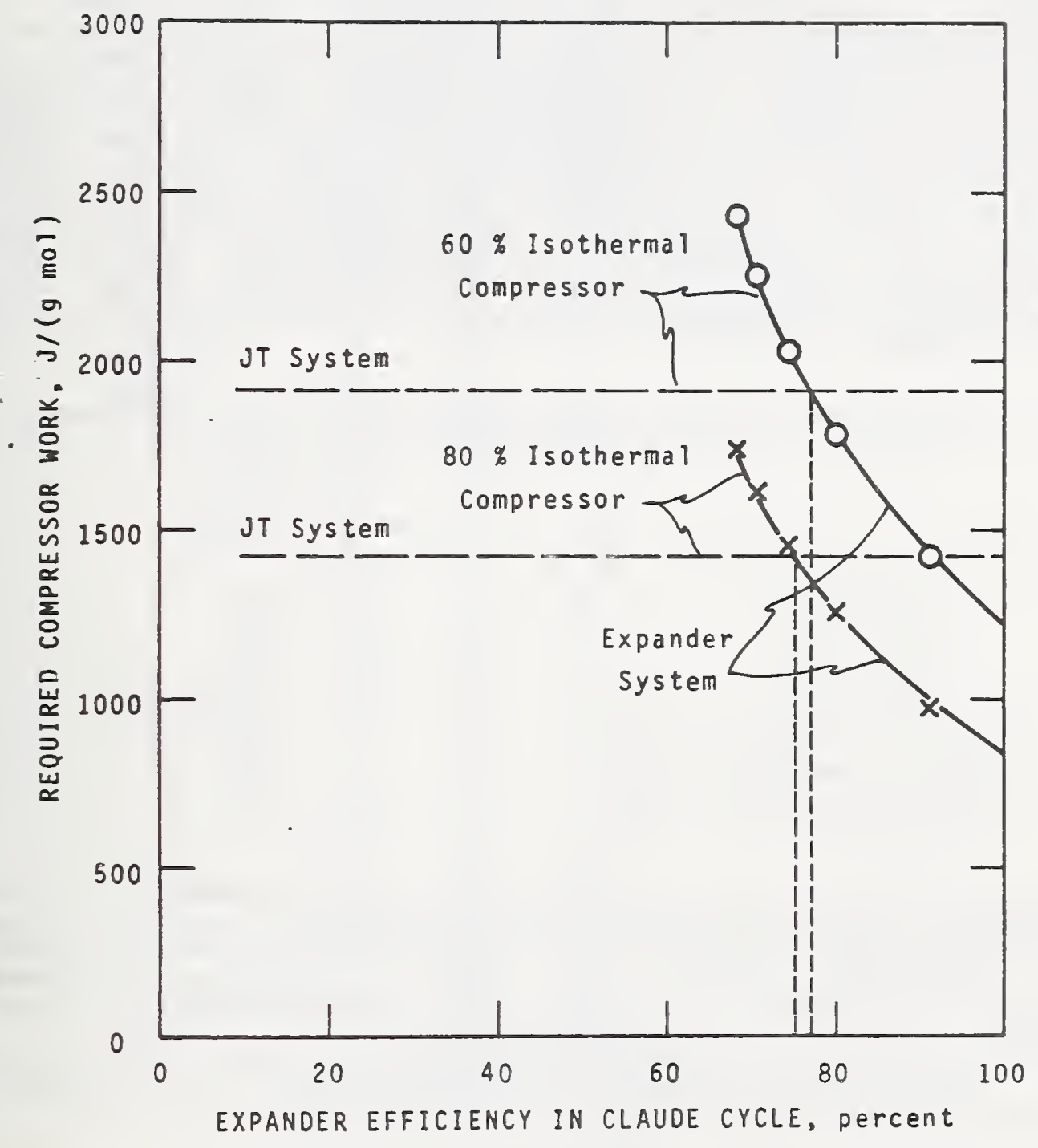

Figure 1.13. The Claude module expander efficeincy required to provide eoud performance between the Claude module and the nitrogen module using a UT valve. 


\title{
1.3.2.1. The design of a practical hydrogen Liquefier
}

Of the many cycles shown on table 1.2, some are not suited for use with real expanders and compressors because of the high operating pressure ratios assumed for the components. Many of the problems associated with compressing hydrogen at room temperature using rotary compressors also apply to turbo-expanders, i.e. low pressure ratio capability per stage. These pressure ratio problems become less severe as the operating temperature of the turbo-expanders decreases. One possible solution to the high temperature expander problem is to replace all the hydrogen expanders above the condensing temperature of liquid nitrogen with a nitrogen precooler refrigerator since nitrogen is much more amenable to expansion and compression in turbo-machinery. A theoretical study of such a cycle [8] indicates an overall hydrogen liquefier efficiency of 36 percent which resulted from the assumed expander and compressor efficiencies shown in table 1.5. The compressor efficiencies shown in table 1.5 are adiabatic instead of the isothermal efficiency used in this study. The theoretical study of the hydrogen liquefier using nitrogen precooling yielded liquefier efficiencies comparable to those determined in this study for an all hydrogen liquefier.

Table 1.5 Assumed compressor and expander efficiency used to determine a hydrogen liquefier efficiency by Linde [8].

Nitrogen Compressor

\author{
Efficiency \\ Percent Adiabatic
}

$\begin{array}{ll}\mathrm{N}_{2} \text { Recycle } & 80 \\ \mathrm{~N}_{2} \text { Booster } & 65 \\ \mathrm{~N}_{2} \text { Makeup } & 75 \\ \text { ogen Compressors (all) } & 80 \\ \text { ogen Expanders (all) } & 79 \\ \text { ogen Expanders (all) } & 84\end{array}$

A possible theoretical cycle successfully using high temperature turboexpanders instead of nitrogen precooling in an all-hydrogen liquefier is shown in figure 1.14. This cycle would use four Brayton modules in the precooler together with a wet expander cold end. The interface fluid state conditions at points 4,5 and 6 are shown on table 1.6 . These inlet conditions of the wet expander cold end result in only a slight precooler flow imbalance $\left(\mathrm{m}_{6} / \mathrm{m}_{5}\right)$. The low flow imbalance allows a relatively low pressure ratio across each expander. Increasing the number of expanders decreases the pressure ratio across each expander further as shown in figure 1.15.

Table 1.6 Interface fluid state points for the all Brayton module liquefier.

PT $\quad P$

(figure 1.14) atm

$\begin{array}{lll}4 & 5 & 36.00 \\ 5 & 1.2 & 35.51 \\ 6 & 1.28 & 36.00 \\ 7 & 1.23 & 21.00\end{array}$

$\mathrm{T}$

K

21.00
$\mathrm{H}$

$\mathrm{J} /(\mathrm{g} \cdot \mathrm{mol})$

1724.69

1781.36

831.84

$-498.15$
$S$

$\mathrm{J} /(\mathrm{g} \cdot \mathrm{mol} \cdot \mathrm{K})$

77.008

89.783

74.663

16.955 m

1.00000

1.00015

0.16329

0.16314 


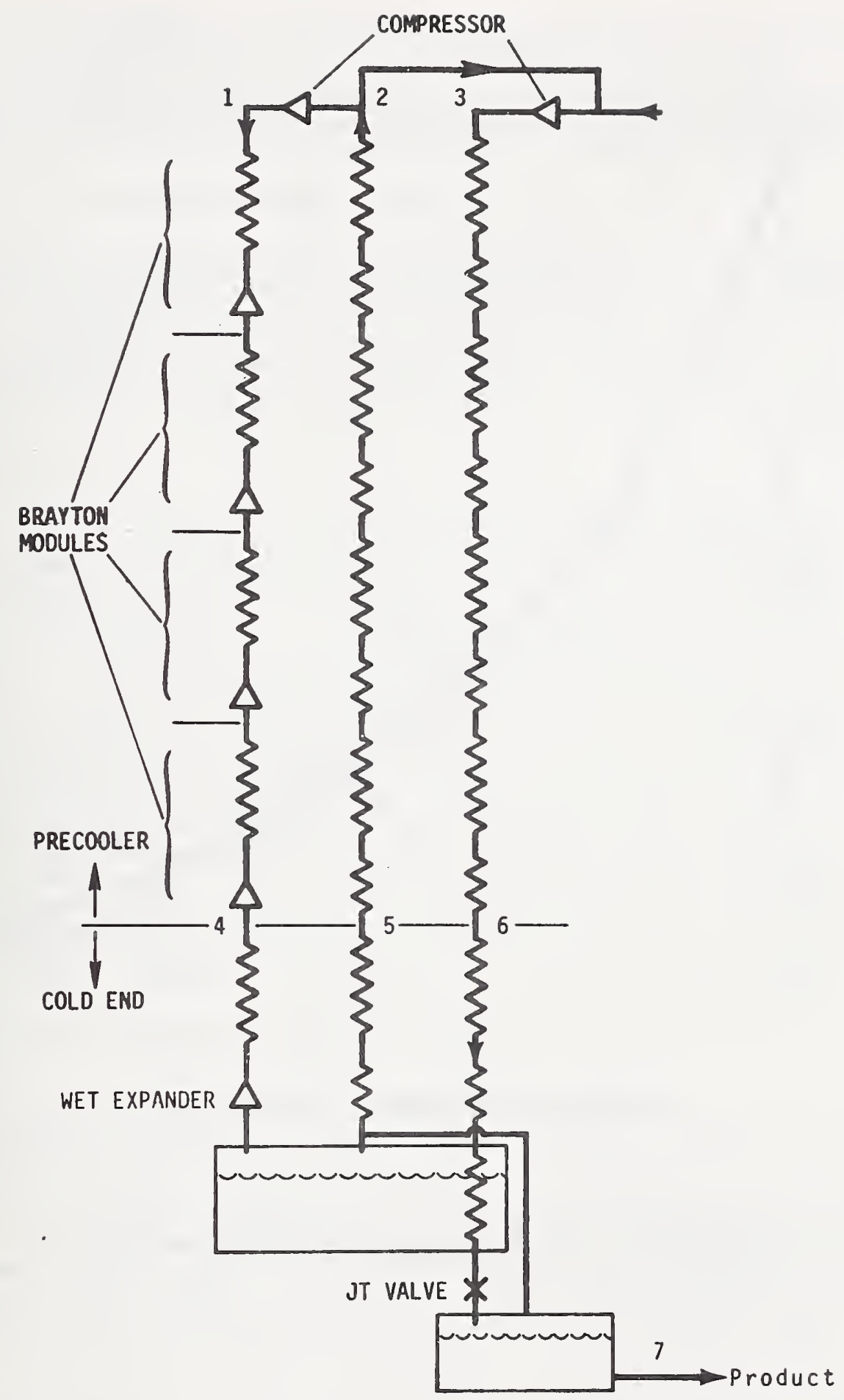

Figure 1.14. A liquefier using all Brayton modules. 


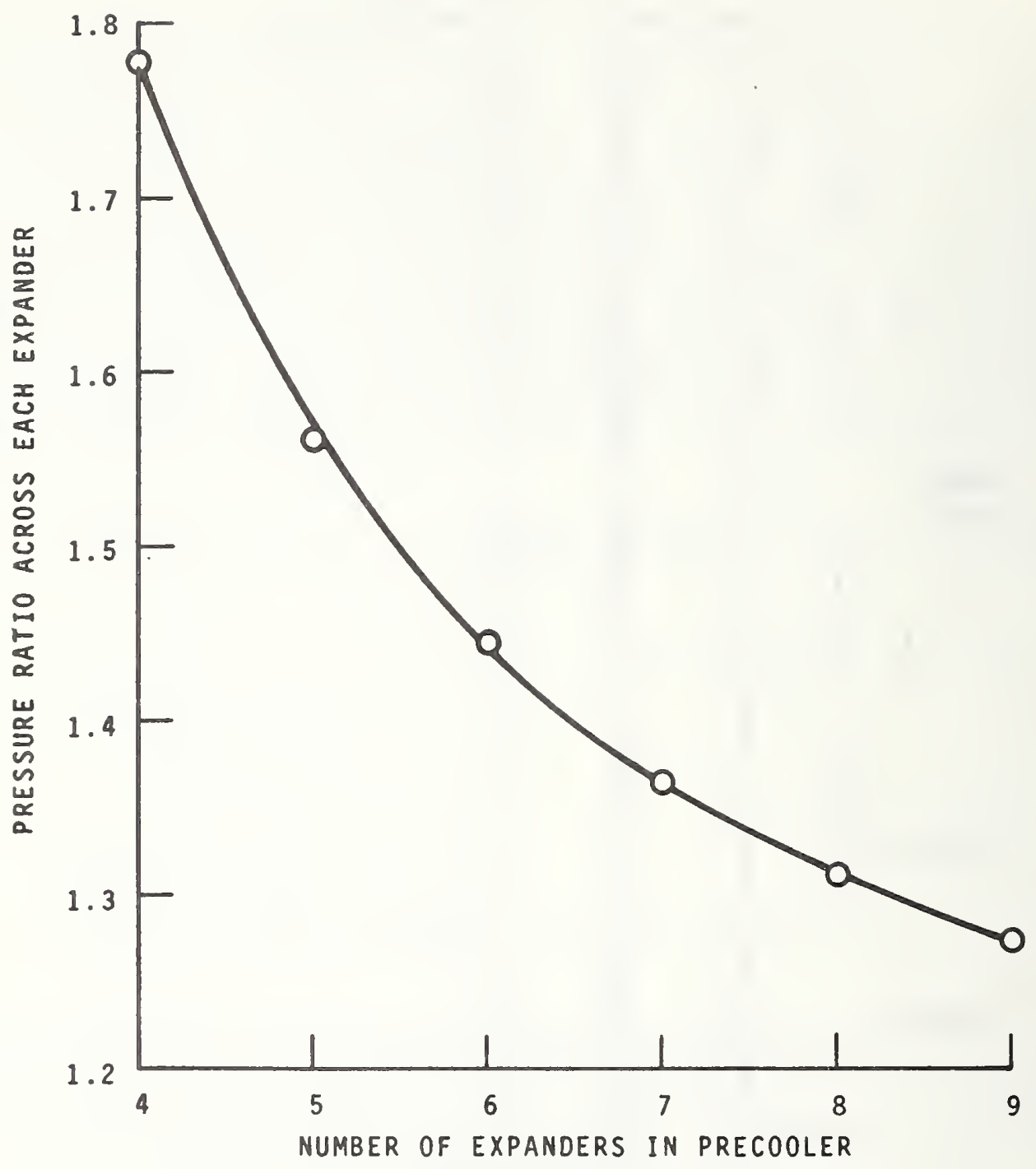

Figure 1.15. The pressure ratio across individual Brayton modules as a function of the number of modules. 
Figure 1.16 shows the variation in liquefier efficiency as a function of the number of expanders. Again the liquefier efficiency is based on 80 percent isentropic expanders, 60 percent isothermal compressors, and a heat exchanger size parameter of around $500 \mathrm{~J} /(\mathrm{mol} \cdot \mathrm{K})$. By judicious choice of the temperature level between each Brayton cycle module, the pressure ratio of each expander could be adjusted to exactly match its optimum operating requirements.

\subsection{Comparison Between Defined Cycle and Real Gas Cycle}

The calculated efficiencies of the hydrogen liquefier compare well with the efficiencies found earlier for a defined cycle as shown on figure 1.17 . Two bands are shown for the defined cycle efficiency; one band is for a constant isothermal expander efficiency of 80 percent, while the other is for a constant isothermal expander efficiency of 100 percent. The band width shows the maximum and minimum effect of pressure drop on the defined cycle efficiency. Several points show comparable calculated efficiencies for the real gas liquefier.

The efficiencies of the theoretical defined cycle and the theoretical real cycle compare well even though the final expansion devices of the two cycles are quite different. The defined cycle uses a theoretical isothermal expander as the final expansion device while the real cycle can use a JouleThomson expansion valve, a wet expander, or an expansion ejector. The defined cycle interface temperature - the temperature between the final expansion device and the precooler - is fixed at the normal boiling temperature of parahydrogen. On the other hand the interface temperature for the real cycle is chosen for each final expansion device to maximize liquefier efficiency. The interface temperature of the real cycle is always greater than the normal boiling temperature of parahydrogen. Because the interface temperature is higher for the real cycle than for the defined cycle, changing the precooling expander efficiencies can affect the overall efficiency of the two cycles differently. When the real cycles uses a Joule-Thomson valve the interface temperatures are nearly the same as the defined cycle and this difference does not appear (see figure 1.17). But the interface temperature for a real cycle using a wet expander or an expansion ejector is higher. In this case changing the precooling expander efficiencies changes the liquefier efficiency differently which leads to a mismatch at the 60 percent precooler expander efficiency point. However, the variance is within the bands shown on figure 1.17 .

\subsection{Conclusions}

The efficiency of hydrogen liquefiers is dependent upon expander efficiency, compressor efficiency, and to a much lesser extent on the heat exchanger size and pressure drop. The cold end losses account for about one to two percent of the total compressor power, so substituting the more reversible wet expander or expansion ejector for the Joule-Thomson valve has little effect on the liquefier efficiency. The cycle efficiencies obtained in a hydrogen gas system compare favorably with the ultimate efficiencies derived for a defined cycle using an ideal gas. This direct comparison reinforces the validity of the hydrogen gas calculations, and shows no particular penalty due to the non-ideal characteristics of the hydrogen gas.

The type of cycle (Brayton, Claude, or Cascace) used in the liquefier has a minimal effect on the efficiency of a hydrogen liquefier. The liquefier cycle chosen should be based primarily on using available expanders and compressors in their most efficient operating situations and on the economics of using large heat exchangers with resulting low $\Delta T^{\prime}$ s and pressure crops. The Claude cycle arrangement of precooling modules is most amenable for use in a low pressure ratio cycle because the precooling load is absorbed by increasing the expander flow instead of increasing the expander pressure ratio as in the brayton cycle module. On the other hand the most efficient use of 


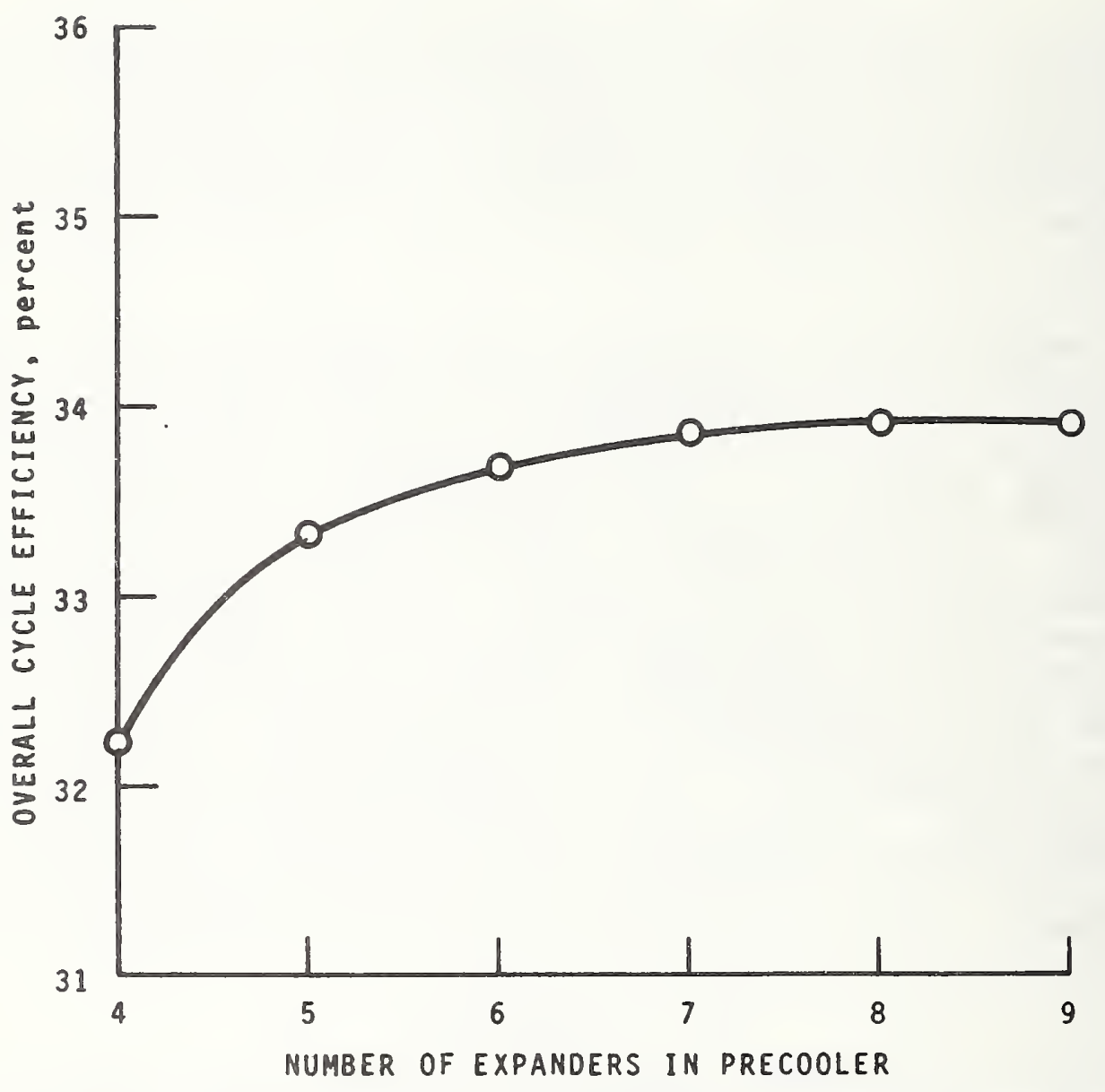

Figure 1.16. Liquefier efficiency as a function of the number of Brayton modules. 


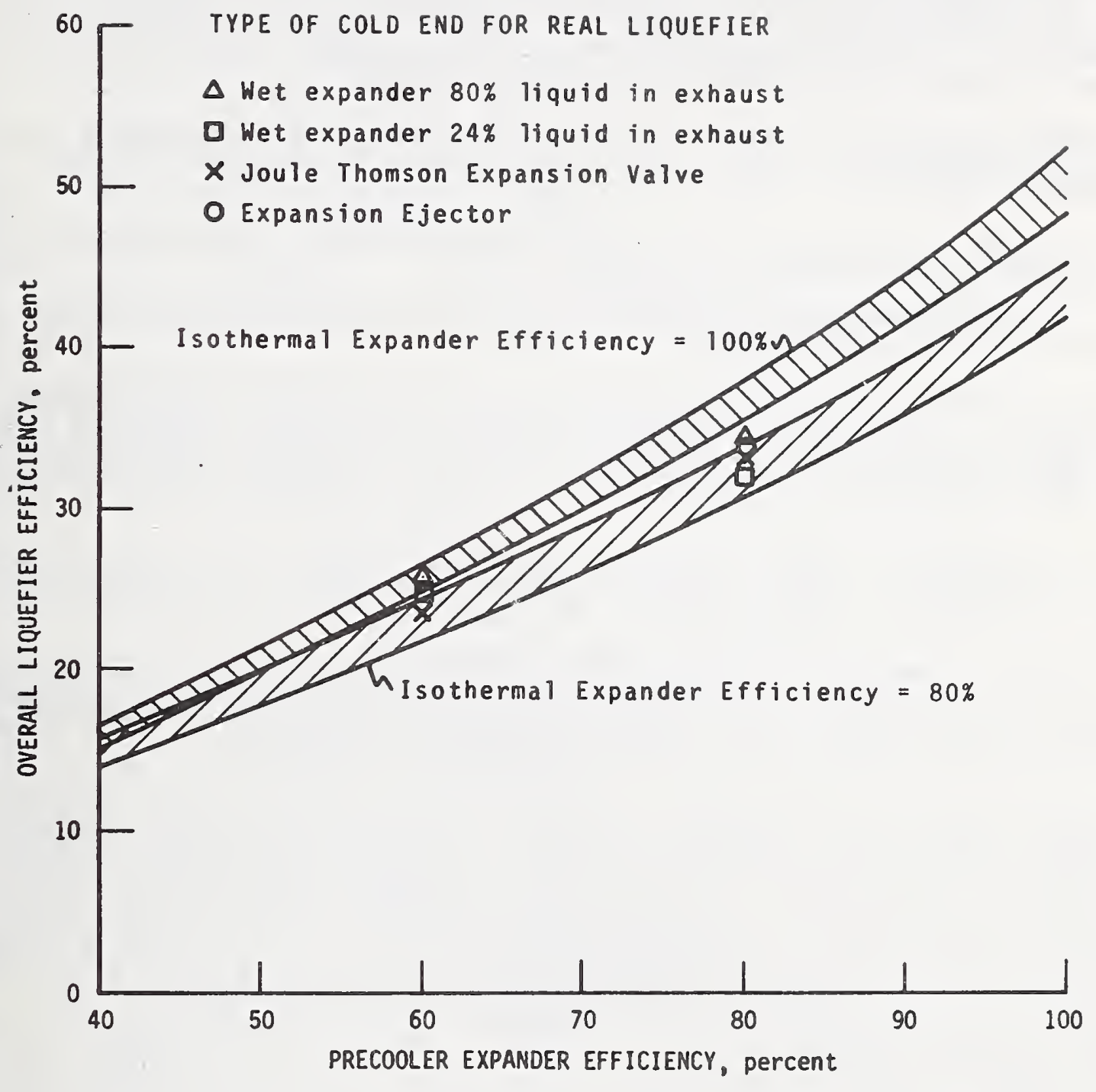

Figure 1.17. Comparison of real liquefier efficiency with the defined cycle efficiency. 
the Claude modules (placing the expanders such that the inlet temperature of a following expander is nearly the same as the discharge temperature of a preceding expander) requires the use of many low pressure ratio expanders to cover the temperature span required in the liquefier. For low precooling loads (low product stream flow rates) the Brayton cycle module is particularly suitable for centrifugal expanders because the expanders operate at raised pressure levels with relatively low pressure ratios.

Actual liquefiers could not achieve the efficiencies determined from any of the theoretical cycles. Among the reasons for the lower actual efficiencies are:

1. losses due to heat leak to the cold portions of the liquefier are not included in the theoretical cycles.

2. Any input power required to purify the hydrogen supply to the liquefier has not been included.

3. A continuous equilibrium conversion from normal to parahydrogen was assumed. In an actual liquefier the conversion would probably be nonideal requiring removal of some of the conversion energy at temperatures lower than equilibrium. This conversion at lower temperatures would also reduce the actual liquefier efficiency.

4. Hydrogen leakage from low temperature components such as expanders would significantly reduce overall liquefier efficiency. No leakage was allowed in the theoretical cycles.

5. The theoretical calculations assumed the recovery of the total expander output power. In an actual liquefier recovery of the total expander power is not possible due to inefficiencies in the mechanical or electrical interface between the expanders and the liquefier compressor.

The results of these studies indicate that with a 60 percent efficient isothermal compressor, 80 percent adiabatic precooling expanders, and an 80 percent isothermal expander, the maximum liquefier efficiency attainable is 40 percent (figure 1.2). Losses due to system pressure drops and heat exchanger temperature differences reduces the defined cycle efficiency to 34 percent (figure 1.3) and 30 percent (figure 1.4). A reasonable efficiency for a practical liquefier may lie somewhere between 30 and 34 percent without considering other losses such as heat leak to the cold components. One would expect that an efficiency of 30 percent may be the practical limit for liquefiers using state-of-the-art components. Very large compressors may exhibit isothermal efficiencies approaching 70 percent; the practical limit of liquefier efficiency would then be 35 percent. Based on this analysis, the currently reported efficiencies of 30-35 percent for industrial hydrogen liquefiers show good design and optimization. Increasing the compressor and/or expander efficiency has the highest potential for increasing the overall liquefier efficiency.

Because of the large dependence of the liquefier efficiency on compressor efficiency, a hydride compressor was investigated. The hydride compressor using the waste heat from a primary compressor is discussed fully in the Appendix. The hydride compressor proved to be no more efficient than conventional compressors.

Since hydrogen liquefier efficiency is primarily dependent upon the efficiency of the expanders and compressors, no large increase in liquefier efficiency can be expected in the near future. Both expanders and compressors have had a long development history, and the probability of step increases in their efficiency is quite remote. 
1.6. Nomenclature

A

C

$\mathrm{C}_{\mathrm{p}}$

h

$\Delta \mathrm{h}_{\mathrm{a}}$

$\Delta \mathrm{h}_{\mathrm{S}}$

k

$\mathrm{L}_{\mathrm{C}}$

$\mathrm{L}$ e

Lej

$\mathrm{L}_{\mathrm{JT}}$

In

'n iso

in pre

$\mathrm{N}_{\text {exp }}$

$\mathrm{P}$

Pac

$\mathrm{P}_{\text {ci }}$

Pr

$Q$

R

s

T

${ }^{\mathrm{T}}$

$\mathrm{T}_{\mathrm{H}}$

$\Delta \mathrm{T}_{\mathrm{L}}$

$T_{\text {in }}$

Tout
Heat transfer area on one side of a counterflow heat exchanger.

Constant used to define heat exchanger temperature difference $C=\Delta \mathrm{T} / \mathrm{T}$.

Constant pressure specific heat.

Specific enthalpy.

Actual specific enthalpy change.

Isentropic specific enthalpy change.

Ratio of specific heat, 1.404 was used in the calculations for hydrogen.

Compressor loss.

Expander loss.

Expansion ejector loss.

Joule Thomson valve loss.

Mass flow rate refers to total mass flow rate.

Mass flow rate through the isothermal expander.

Total mass flow rate through the precooling expanders.

Number of precooling expanders.

Absolute pressure.

Actual isothermal compressor power.

Ideal isothermal compressor power, real gas.

Pressure ratio, high pressure/low pressure.

Heat flow.

Gas constant.

specific entropy.

Absolute temperature.

Absolute temperature of the cold end of the liquefier, 20.268 K was used in the hydrogen calculation.

Absolute temperature of the high temperature end of the hydrogen liquefier; $300 \mathrm{~K}$ was used.

Local heat exchanger temperature difference.

Absolute inlet temperature.

Absolute outlet temperature. 


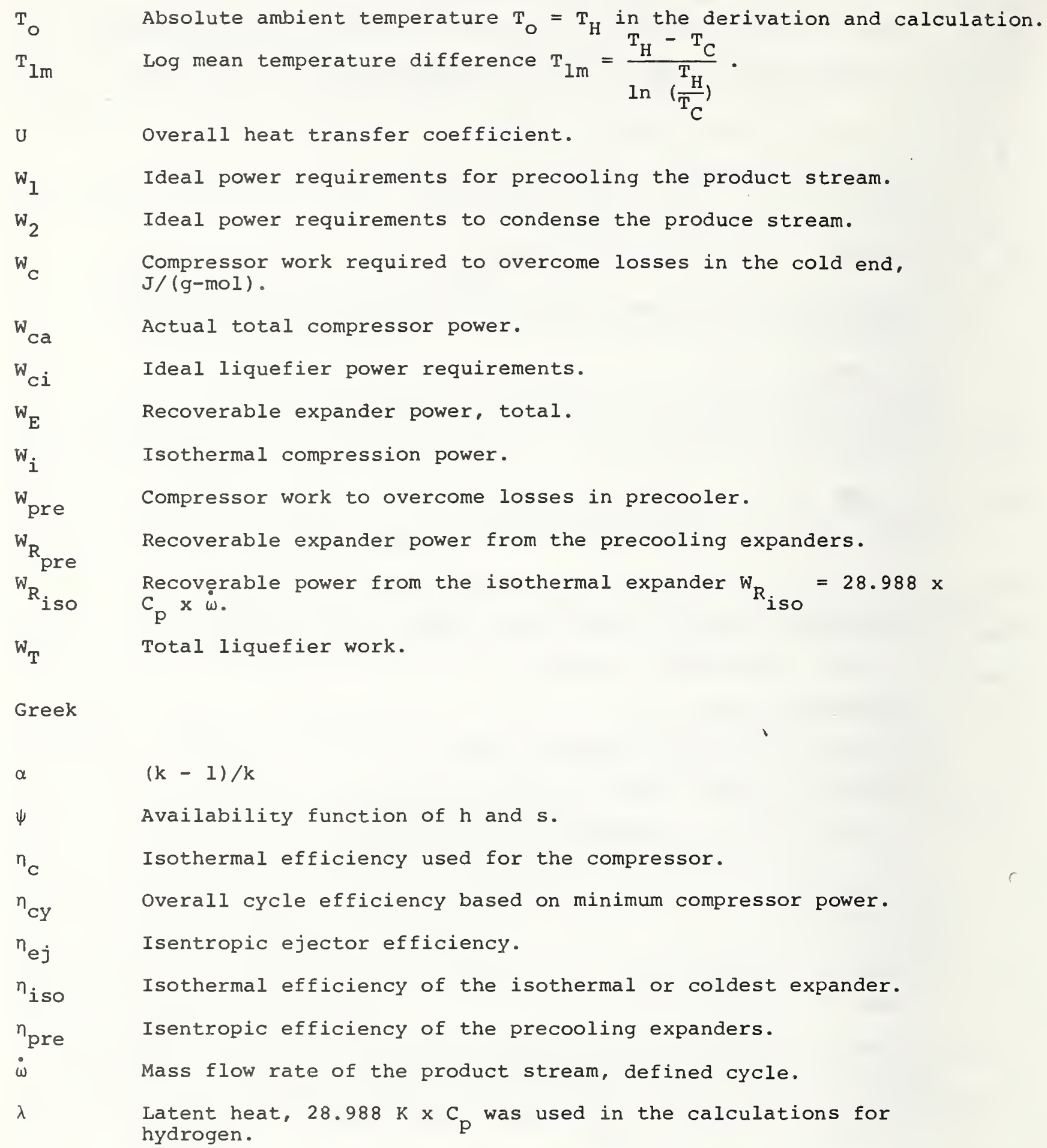




\subsection{References}

[1] Parrish, W. R. and Voth, R. O., Cost and availability of hydrogen, Nat. Bur. Stand. (U.S.) Special Publication 419, (J. Hord, Ed.) (May 1975).

[2] Collins, S. C. and Cannaday, R. L., Expansion machines for low temperature processes (Oxford Univ. Press, 1966).

[3] Grassmann, Von P. and Kopp, J., On the choice of temperature difference and heat transfer coefficient in heat exchangers, Kalletechnik 9 , No. $10,306-308$ (1957).

[4] Jacobs, R. B., The efficiency of an ideal refrigerator, Advances in Cryogenic Engineering, 7, Ed. K. D. Timmerhaus, pp. 567-571 (Plenum Press, Inc., New York, NYY, 1962).

[5] Rietdijk, J. A., The expansion-ejector, a new device for liquefaction and refrigeration at $4 \mathrm{~K}$ and lower, Commission 1 , International Institute of Refrigeration (1966).

[6] Daney, D. E., McConnelI, P. M. and Strobridge, T. R., Low temperature nitrogen ejector performance, Advances in Cryogenic Engineering, 18 ,

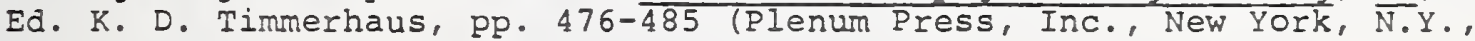
1973).

[7] Daney, D. E., Refrigeration for an $8 \mathrm{~K}$ to $14 \mathrm{~K}$ superconducting transmission line, Nat. Bur. Stand. (U.S.) NBSIR 74-375, (Oct. 1974).

[8] Survey study of the efficiency and economics of hydrogen liquefaction, NASA CR-132631, prepared by the Iinde Division of Union Carbide Corporation, 70 pages ( 1975 ).

[9] Cumings, D. L. and Powers, G. J., Storage of hycrogen as metal hydrides, Ind. Eng. Chem. Process Des. Develop. 13 (2), 182 (1974).

[10] Wiswall, R. H. and Reilly, J. J., Metal hydrides for energy storage, Proc. of the 7th Intersociety Energy Conversion Engineering Conf., 1342 (1972). 


\subsection{APPENDIX}

\section{Hydride Compressors}

W. R. Parrish

\subsubsection{Introduction}

As pointed out in section 1.5 , one way to significantly improve the liquefaction cycle efficiency is to increase compressor efficiency. This appendix considers the feasibility of using the waste heat generated by a conventional compressor to drive a metal hydride "compressor." Calculations show that there is too little high quality heat to make this hybrid compressor system worthwhile.

\subsubsection{Properties of metal hydrides}

This section gives a terse explanation of the properties of metal hydrides; more complete details are presented elsewhere $[9,10]$. If certain metals are exposed to gaseous hydrogen the following reaction takes place

$$
\mathrm{M}+\frac{\mathrm{N}}{2} \mathrm{H}_{2} \rightleftarrows \mathrm{MH}_{\mathrm{N}} \text {. }
$$

The extent of this reversible reaction depends upon the pressure of hydrogen. However, over the major portion of the reaction the equilibrium pressure remains nearly constant. This "plateau" pressure varies with temperature according to

$$
\text { In } P=a+\Delta H / R T
$$

where $\mathrm{P}$ is the pressure, $\mathrm{a}$ is a constant, $\Delta \mathrm{H}$ is the heat of formation, i.e. hydration for eq. (AI), $\mathrm{R}$ is the gas constant and $\mathrm{T}$ is the absolute temperature. For the hydride of interest here, $\Delta \mathrm{H}$ is negative. This means that the plateau pressure increases with increasing temperature. It also implies that, if a constant temperature is required, heat must be removed during hydride formation (charging) and heat must be added during dissociation (discharging).

\subsubsection{Hydride compressor system}

Figure 1.18 shows a schematic of the compressor system considered here. Hydrogen enters the system at pressure $\mathrm{P}_{1}$ and ambient temperature, part of the hydrogen ( $1-f$ ) goes through a conventional compressor while the remainder, $f$, goes to the hydride beds. If necessary, the flows are recombined and sent through another compression stage. Heat removed from the compressor is used to heat the hydride beds. Three parallel beds are needed; while one bed is discharging, another bed is charging. The third bed is being cooled or heated, depending upon what portion of the cycle it is in. The cold bed is being charged at pressure $P_{1}$ as the warm bed is being discharged at pressure $\mathrm{P}_{2}$.

Assuming that no external heat is added, the maximum value of $f$ depends upon how much of the heat produced by the compressors can be added to the warm bed as it discharges. Table I.I shows this dependence for three different systems; it also shows the possible increase in efficiency of this type of system. The heat duty of the compressor is calculated by assuming that all of the work going into the compressors is converted to heat. The compressor efficiency for estimating the heat duty is assumed to be 80 percent of adiabatic. (The heat duty calculated here for system II was five percent less 


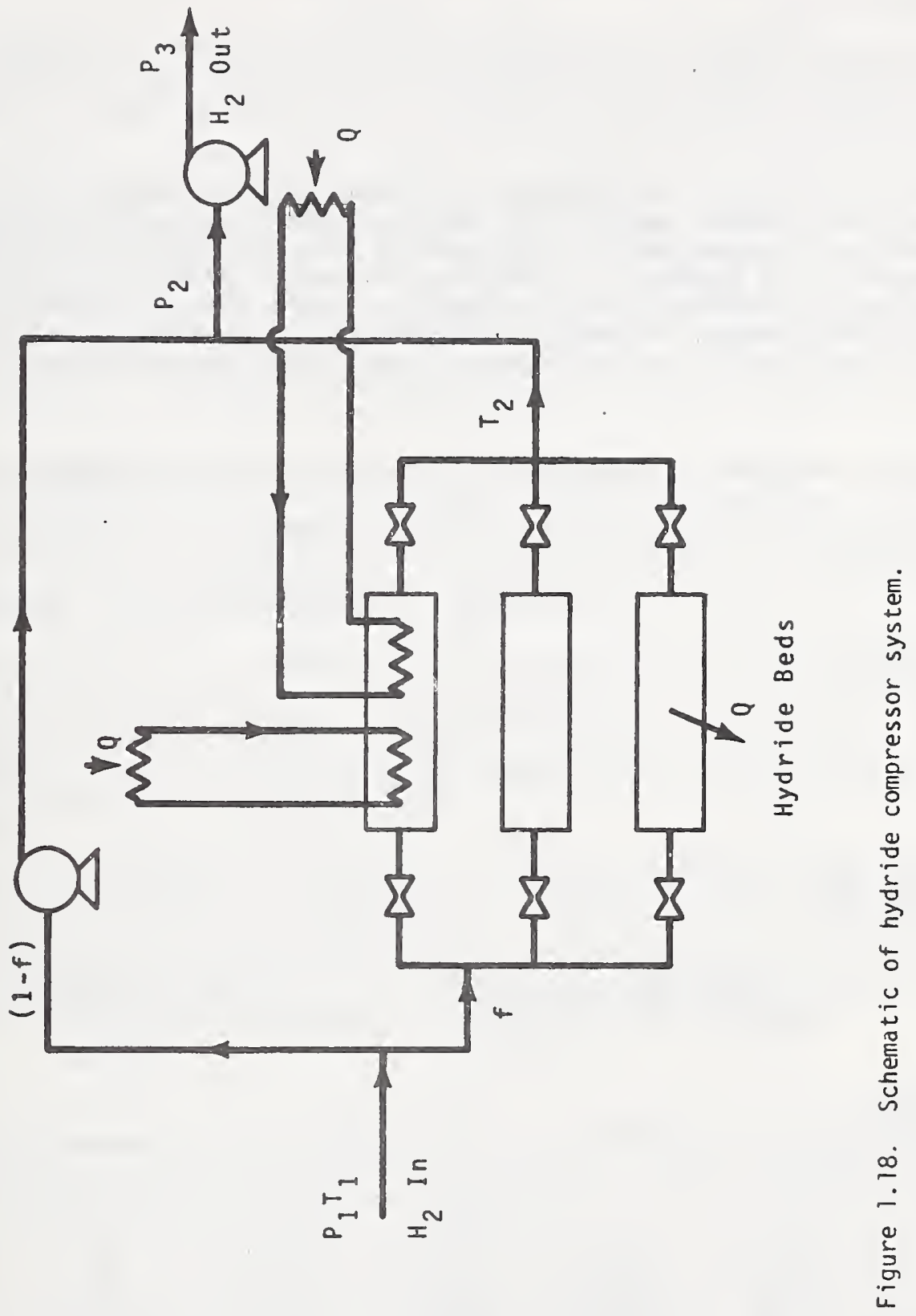


than that given by a more detailed compressor design for the same inlet and outlet pressures [9]).

The fraction of heat utilized depends upon the operating temperature range of the compressor cooling fluid. If water is used at temperatures between 80 and $200^{\circ} \mathrm{F}$, less than half of the heat could be used to keep the discharging bed warm.

Based on table A.I it is unlikely that the hydride compressor concept could ever become a useful system, at least at the pressures considered here. This conclusion is independent of the type of hydride considered because of the chemical nature of hydrides. Ideally, one would desire the hydride to have a low value of $\Delta \mathrm{H}$ and a rapid change in pressure with temperature. However, as eq. (A2) shows, these two conditions are contradictory since they would require the value of $\Delta H$ to be small and large simultaneously.

Table A.1. Results of feasibility of using hydride compressors. Hydride Material
$\Delta H, \mathrm{~kJ} / \mathrm{g}-\mathrm{mol} \mathrm{H}_{2}$ [2]
$\mathrm{P}_{1}$, atm.
$\mathrm{P}_{2}$, atm.
$\mathrm{P}_{3}$, atm.
Maximum Hydride $\mathrm{Bed}$
Temperature $\mathrm{T}_{2},{ }^{\circ} \mathrm{C}$
I<smiles></smiles>
$-39$

1.0

6.8

6.8

71 system

II

$$
\mathrm{VH} \leftrightharpoons \mathrm{VH}_{2}
$$$$
-40
$$

2.8

16.7

40.0
II I

$\mathrm{FeTi} \leftrightarrows \mathrm{FeTiH}$

$-23$

4.7

30.0

66.7

64
Fraction of Flow Through Hydride Bed, f
Apparent Overall Adiabatic Compressor Efficiency Percent
Fraction of Compressor Heat Put Into Discharging Hydride Bed

$\begin{array}{cccc} & \text { I } & \text { II } & \text { III } \\ 0.00 & 0 & 0 & 0 \\ 0.25 & 0.036 & 0.050 & 0.087 \\ 0.38 & 0.053 & 0.074 & 0.129 \\ 0.50 & 0.069 & 0.097 & 0.169 \\ 1.00 & 0.129 & 0.182 & 0.317\end{array}$

System

$\begin{array}{llr}I & \text { II } & \text { III } \\ 80 & 80 & 80 \\ 83 & 83 & 83 \\ 84 & 84 & 84 \\ 86 & 85 & 86 \\ 92 & 90 & 92\end{array}$


W. R. Parrish

2. SUMMARY

This chapter considers the technical feasibility of recovering a portion of the energy which goes into liquefying hydrogen. Three possible recovery systems are analyzed; two of which could have direct application in the electrical utility industry. The first system uses a liquid hydrogen pump, a heat exchanger and a room temperature expander for shaft work recovery. Depending upon the desired outlet pressure it is possible to recover over 60 percent of the ideal work of liquefaction. This is the additional amount of work available at the use point from the use of liquid hydrogen instead of gaseous hydrogen at $1.0 \mathrm{~atm}$. Burning a fraction of the hydrogen to heat the expander inlet gas is an unattractive option.

If the refrigerating capacity of liquid hydrogen can be utilized in an air separation plant, the energy recovery can be even greater. For example, if such a system is used to feed a hydrogen-oxygen MHD power generator, there would be an effective energy savings of 105 percent of the ideal work of liquefaction. However, if the system feeds a hydrogen-oxygen fuel cell only about 20 percent could be recovered.

The third energy recovery system involves using hydrogen as the refrigerant for extracting rare gases from the atmosphere. Because of the anticipated supply and demand picture, helium is probably the only rare gas for which there will be a large future demand. However, calculations show that a helium recovery unit could produce at best only $10^{-5}$ moles of helium for each mole of liquid hydrogen vaporized.

Thus, it is technically feasible to recover an appreciable fraction of the energy of liquefaction if energy is the desired product. This energy recovery has the net effect of reducing the energy cost of producing liquid hydrogen; this, in turn, makes the storage of hydrogen as a liquid more attractive. However, the concept of using liquid as the refrigerant for recovering rare gases from the atmosphere is much less attractive.

\subsection{Introduction}

In the future the most probable means of storing large quantities of energy derived from solar and/or nuclear sources will be synthetic fuels. Based on availability, environmental and economic considerations, the most promising synthetic fuel is hydrogen. Three options exist for storing large quantities of molecular hydrogen: compressed gas, metal hydride and liquid. Compressed gas might be an attractive option if depleted oil and gas fields are available; metal hydride technology is advancing rapidly but both the technical and economic feasibility still are unproven. Of the three options, only liquid hydrogen offers proven storage technology which makes it a strong contender in many potential applications.

However, a major drawback to storing hydrogen as a liquid is the amount of energy required for liquefaction; the ideal work of liquefaction is 28.7 $\mathrm{KJ} / \mathrm{g}-\mathrm{mol}$ or roughly 10 percent of the lower heating value of hydrogen. Due to liquefier inefficiencies, the actual work of liquefaction is roughly three times greater than ideal [1].

Any liquefaction energy recovered would have the net effect of lowering the energy cost of producing liquid hydrogen. This paper investigates the feasibility of recovering a portion of the liquefaction energy as previously 
suggested [2]. Three types of systems are considered. The first type utilizes the refrigeration capacity of liquid hydrogen for three electrical power generators: gas turbines, fuel cells and MHD generators; the applications are directed toward (but not restricted to) the electrical utilities because they represent a potentially large consumer of hydrogen. The feasibility of using liquid hydrogen as the primary refrigerant for separating air and for recovering rare gases from the atmosphere are also evaluated.

\subsection{Electrical Utility Applications}

\subsubsection{Liquefaction energy recovery factor}

To measure the benefit of recovering liquefaction energy we define the Liquefaction Energy Recovery Factor (LERF) as

$$
\text { LERF }=\left(E_{W}-E_{W / O}\right) / E_{L I}
$$

where $E_{W}$ is the electrical power output per $g$-mol of hydrogen with liquefaction energy recovery, $E_{w / O}$ is the power output without recovering liquefaction energy and $E_{L I}$ is the ideal work of liquefying one g-mol of hydrogen. The liquefaction energy recovery factor based on actual work of liquefaction is obtained by multiplying eq. (2.1) by the efficiency of liquefaction plants relative to the Carnot efficiency. The efficiency of large liquefaction plants is expected to range from 33 to 40 percent.

To keep the calculations on a common basis the values in eq. (2.1) are calculated on the assumption that the fuel enters the system at $1.0 \mathrm{~atm}$. Therefore $E_{L I}$ is based on 1.0 atm suction pressure as is $E_{W / 0^{i}}$ likewise, the values of $E_{w}$ are based on 1.0 atm liquid entering the recovery system. If the electrical power generator operates above $1.0 \mathrm{~atm}$, the work of compressing hydrogen to the operating pressure is accounted for in $E_{w / O}$ by assuming $a$ hydrogen compressor operating at 60 percent efficiency based on isothermal compression. If the recovery system is a net producer of shaft work it is assumed that this work is converted to electrical energy at a 95 percent efficiency.

\subsubsection{Liquefaction energy recovery systems}

This section considers two classes of liquefaction energy recovery systems. The first takes advantage of the difference in shaft work required to compress a liquid as compared to a gas; however, the refrigeration capability is wasted. The second type of recovery system makes direct use of net shaft work and the refrigeration capacity of liquid hydrogen.

Figure 2.1 shows a schematic of the first kind of energy recovery system. Liquid hydrogen is compressed to some intermediate pressure $\mathrm{P}_{i}$ ' warmed to ambient temperature and then expanded to a given final pressure $P_{0}$ which is equal to the inlet pressure of the power generator; both the liquid pump and expander are assumed to operate at an efficiency of 80 percent of adiabatic. The shaft work is converted to electricity and the hydrogen is sent to the power generator. Also, it is possible to heat the high pressure hydrogen prior to expansion by burning some fraction $f$ of the hydrogen leaving the expander.

Figure 2.2 shows values of LERF for $f=0.0$ as a function of expander inlet and outlet pressure. The calculations are based on the thermodynamic data of McCarty and Weber [3]. For the case when the expander inlet and outlet pressures are equal (i.e., no expander is used) the value of LERF shows the energy saved by compressing liquid instead of gaseous hydrogen. The 


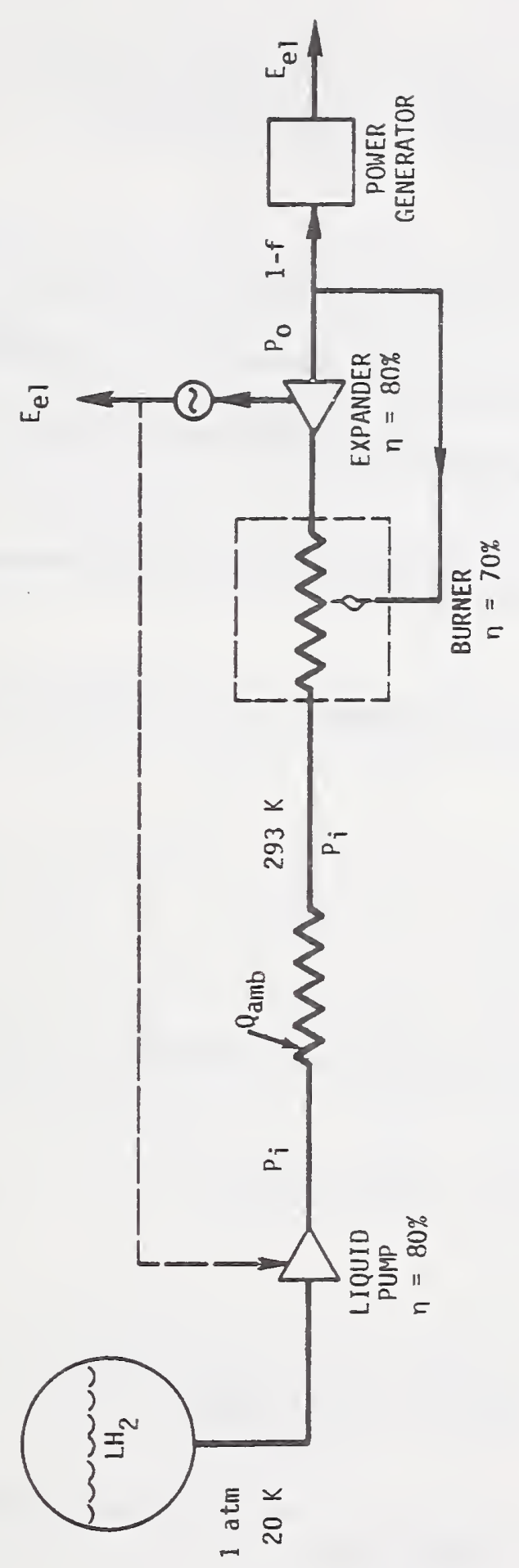

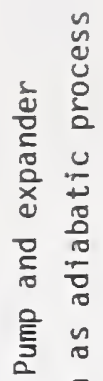

㲾

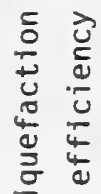

ङ

용

궁

4

$>\frac{1}{2}$

ऐ

苟

둥

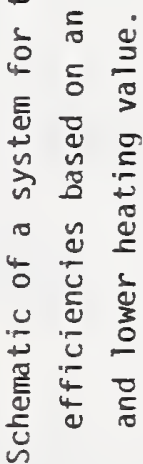

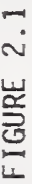


curves show an asymptotic behavior with increasing expander inlet pressure and, as one would expect, the relative gain with increasing inlet pressure decreases with increasing expander outlet pressure. There is little advantage in an expander system if the outlet is greater than $20 \mathrm{~atm}$; however, the energy savings of compressing liquid instead of gas are significant at the higher pressures. It is expected that $\mathrm{H}_{2}-\mathrm{O}_{2}$ MHD generators will operate at 30 atm [9] while fuel cells will operate very close to ambient pressure.

If all of the hydrogen goes to the power generator ( $f=0$ ) the value of LERF is independent of the power generator. However, if some hydrogen is burned the relative efficiencies of the burner, expander, and the power generator must be considered. Figure 2.3 shows how LERF varies with expander inlet pressure and $f$ if a gas turbine having an efficiency of 28 percent (based on LHV) is used. (It is assumed that the burner has an efficiency of 70 percent based on LHV). In this case the expander outlet pressure is 8 atm which corresponds to present-day gas turbines [4]. For expander inlet pressures of less than 115 atm it is better not to burn any hydrogen; higher inlet pressures make burning only a slightly beneficial option. Over the range of values considered here, LERF is nearly a linear function of $f$. Therefore the optimum value of $f$ would be the value of $f$ corresponding to the maximum temperature allowed in the burner. Even though there is little benefit in burning some of the hydrogen, figure 2.3 shows that it is possible to obtain a LERF of 40 percent by recovering shaft work only.

Similar calculations for two other power generators, MHD and fuel cells, show that, at expander inlet pressures of $200 \mathrm{~atm}$ or less, it is better to send all of the hydrogen to the power generator; this is because they are more efficient than the burner-expander system. Therefore, it is apparent that burning hydrogen is not generally an attractive option.

In the above calculations the refrigerating capacity of liquid hydrogen was wasted. Iiquid hydrogen could be put to the same uses as are being considered for LNG "cold" [5]. However, liquid hydrogen is a more useful refrigerant because of its lower temperature (liquid hyorogen boils at $20 \mathrm{~K}$ while LNG boils at $112 \mathrm{~K}$ or higher). One obvious application is to use liquid hydrogen as a coolant in an air separation plant. The ability to produce gaseous oxygen on-site could have energy, economic and environmental benefits. Assuming an ideal, i.e. reversible, process it would be possible to produce a stoichiometric quantity of oxygen from air by recovering the ideal work of liquefaction for hydrogen without any additional work. A more detailed, and lengthy, analysis (more details are given in the Appendix) shows that at best, only 40 percent of the stoichiometric could be produced without additional work. Thus additional work is required if a stoichiometric amount of oxygen is desired. Even so, the more realistic calculations point out the following advantages for using liquid hydrogen as a refrigerant in an air plant:

1. Based on the ideal work of separation $\left(6100 \mathrm{~J} / \mathrm{g}-\mathrm{mol}\right.$ of gaseous $\mathrm{O}_{2}$ product), it is possible to obtain an efficiency of 18 percent for an air plant using a single distillation column. This can be compared to the efficiency of 10 to 12 percent reported by Bliss and Dodge [6] for conventional single column plants and 19 percent for large dual column air plants as given by springmann [7].

2. If the column could be operated at $0.33 \mathrm{~atm}$, the efficiency could increase tonearly 34 percent.

3. If high pressure gaseous oxygen is the desired product, using liquid hydrogen as a coolant makes it attractive to compress liquid instead of gaseous oxygen. Smith [8] has pointed out that it is normally unattractive to pump liquid oxygen to provide high pressure gaseous oxygen in a conventional air separation plant; however, liquid hydrogen cooling provides enough refrigeration capacity at $90 \mathrm{~K}$ to permit the liquid oxygen to be pumped and expanded to produce net shaft work as earlier described for hydrogen. 


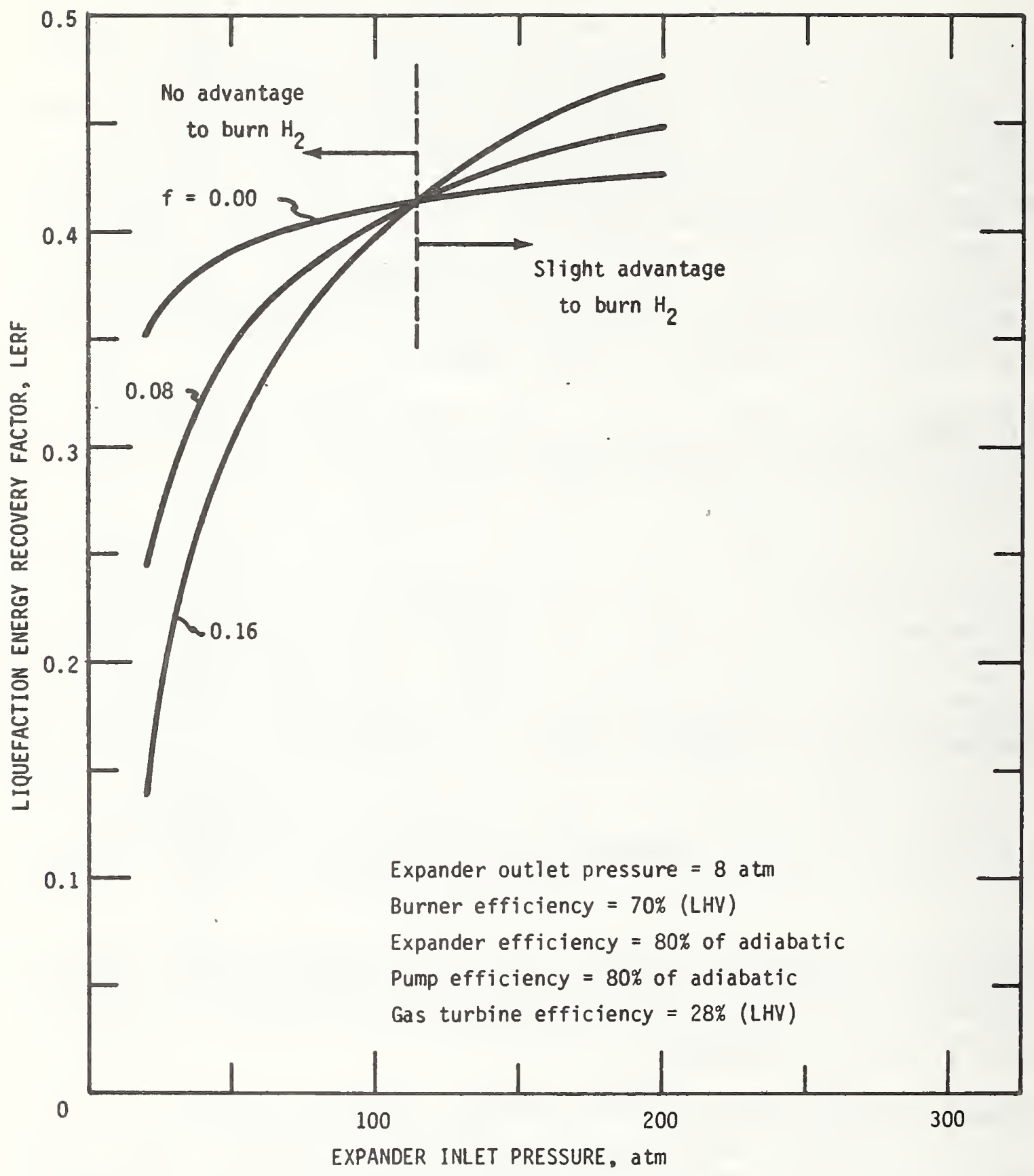

FIGURE 2.3 LERF as a function of expander inlet pressure and mass fraction burned for a pump-expander system in conjuntion with a gas turbine. 
Table 2.1 shows the relative benefits of recovering hydrogen liquefaction energy, with and without utilizing refrigeration, for the MHD generator and fuel cell. The gas turbine option was omitted because gas turbines normally use air. The values of LERF are based on an expander inlet pressure of 200 atm for both hydrogen and oxygen. The calculations for the MHD generator are based on data by Seikel, et.al. [9] for their "option $3^{\mathrm{n}} \mathrm{H}_{2} \mathrm{OO}_{2}$ system; their systems are based on using an air separation plant and on operating the combustor at $30 \mathrm{~atm}$. For this case substantial gains in overall efficiency can be made by using just shaft work as well as shaft work plus refrigeration. In the latter case a LERF value of 0.98 represents one-third of actual energy of liquefaction and a substantial energy saving. There is little benefit from pumping and expanding oxygen because the expander outlet pressure is so high. From an economic standpoint, liquefaction energy recovery should be very attractive since an air separation plant is already required.

The results are quite different in the case of fuel cells. Even after considering the increased efficiency of the $\mathrm{H}_{2} \mathrm{O}_{2}$ fuel cell over the $\mathrm{H}_{2}$-air fuel cell, there is an insufficient gain in LERF to justify using the liquid hydrogen for separating air. Even so, to conserve energy it still would be worthwhile to recover the available shaft work.

\subsection{Recovery of Rare Gases}

The atmosphere is the primary source of all the rare gases except helium, which currently is extracted from natural gas. Table 2.2 gives the approximate atmospheric concentrations of the rare gases. The concentrations of neon, krypton and xenon are quite low but the comercial demand for these gases is also low. Therefore, conventional air plants equipped with recovery systems can produce a sufficient supply of these gases. However, the situation for helium is quite different. Helium is in greater demand than the other rare gases and its demand could significantly increase if there is large-scale implementation of high temperature gas reactors, superconducting transmission lines and/or superconducting magnetic energy storage devices. However, natural gas reserves are depleting rapidly which means that sometime in the future, air will become the primary source of helium. Therefore, the following section considers the feasibility of using liquid hydrogen as a refrigerant for recovering helium from the atmosphere.

Table 2.1. Estimated values of LERF (liquefaction energy recovery factors) for MHD generator and fuel cell based on a 200 atm expander inlet pressure.

\section{NO SHAFT WORK FROM OXYGEN}

$\mathrm{H}_{2}$ Shaft Work Only

$$
\text { MHDI } \quad \text { Fuel Cell }{ }^{2}
$$

$\mathrm{H}_{2}$ Shaft Work + Refrigeration

$$
\begin{array}{ll}
0.58 \quad 0.17
\end{array}
$$

$1 \mathrm{~atm}$ column

0.98

0.18

l/3 atm column

1.26

0.45

SHAFT WORK FROM OXYGEN

$\mathrm{H}_{2}$ Shaft work only

$\mathrm{H}_{2}$ Shaft Work + Refrigeration
I atm column
1/3 atm column
1.04
0.34
1. 31
0.61

$I_{\text {MHD Generator } \eta}=0.65$ based on LHV [9].

2 Fuel cell $\eta=0.51$ for $\mathrm{H}_{2}$-air and 0.58 for $\mathrm{H}_{2}-\mathrm{O}_{2}[10]$. 
Table 2.2. Atmospheric concentration of the rare gases [11].

Component

Neon

Helium

Krypton

Xenon
Composition, ppm by volume

18
5
1
0.09

\subsubsection{Helium recovery process}

The most attractive way to recover helium from air is to condense air under several atmospheres of pressure and at a temperature of 64 to $70 \mathrm{~K}$. Under these conditions the vapor phase will contain roughly 25-40 percent nitrogen, 46-55 percent neon, 15-20 percent helium and 1-4 percent hydrogen [12]; depending upon the temperature and pressure, there could also be 1-4 percent oxygen. The hydrogen and oxygen are removed first using a deoxo reactor. Then the enriched vapor goes to an adsorbant bed operating at $77 \mathrm{~K}$ which removes the nitrogen and neon $[11,12]$.

To estimate the technical feasibility of recovering helium with the above process the practical amount of air throughput per unit of hydrogen vaporized must be considered. Two possible limitations exist. One is a work limitation, i.e. how much air that can be compressed using an expander system for hydrogen as described in section 2.2.2. The other possible limitation is in how much air can be processed for the given amount of refrigeration available.

\subsubsection{Work limitations}

It is assumed here that the helium recovery system will be self-sufficient in energy, i.e. all the necessary shaft work will be derived from gas expanders. If liquid hydrogen is compressed to $200 \mathrm{~atm}$, warmed to room temperature and expanded back to $1.0 \mathrm{~atm}$, there is a net energy output of roughly $5040 \mathrm{~J} / \mathrm{g}-\mathrm{mol} \mathrm{H} \mathrm{H}_{2}$. Then the amount of air compressed is given by

$$
\frac{\text { Moles of air compressed }}{\text { Moles of } \mathrm{H}_{2} \text { vaporized }}=1.9 / \mathrm{ln} \mathrm{P}
$$

where $\mathrm{P}$ is the air compressor outlet pressure in atm. This equation assumes:

1. An air compressor efficiency of 60 percent of isothermal.

2. An expander efficiency of 60 percent of isothermal for the air being discharged from the system; this recovers some of shaft work of the compressor.

3. Gas compression at $300 \mathrm{~K}$.

The air pressure is an operating variable but it should be as high as possible to minimize the nitrogen content of the vapor going to the absorption bed; the lower nitrogen content lowers the hydrogen refrigeration load. The lowest practical pressure would probably be about $1.5 \mathrm{~atm}$. Equation (2:2) then gives 4.7 moles of air per mole of hydrogen. For this case if all of the helium was recovered there would be only $23 \times 10^{-6}$ moles of helium produced per mole of hydrogen vaporized.

However, the work limitation can, in principle, be eliminated by compressing the liquid air, warming and expanding it back to 1.0 atm. By using the above assumptions and by assuming that: 1) air behaves like nitrogen, 2) the pump and expander efficiencies are 80 percent of adiabatic and 3 ) the expailder inlet pressure is $200 \mathrm{~atm}$, one obtains 
Thus, if the air pressure is $2.9 \mathrm{~atm}$, the air expander system could provide all of the compressor work.

\subsubsection{Refrigeration Iimitations}

There are three areas of the helium recovery system where the amount of air processed could be limited by the available refrigeration. The first area is in removing the heat of absorption for neon and nitrogen. Secondly, if the air is to be compressed and expanded to provide shaft work the air stream will be warmed by several degrees Kelvin; the hydrogen must then supply this lost refrigeration. Lastly, the heat exchanger which cools the incoming air stream will not be 100 percent effective and the hydrogen stream must make up the difference.

Considering first the heat of absorption, calculations show that the ratio of helium to hydrogen throughput could be roughly 0.05 ; thus, this would not be a limitation. Taking only the loss of refrigeration due to air compression into account, the maximum air throughput rationcould be only 1.5 . Also, if the heat exchanger has an effectiveness of 0.95 , one again obtains a maximum throughput ratio of 1.5. Therefore, one must conclude that the maximum air to hydrogen throughput ratio is roughly 1.5 ; this implies that at best it be possible to recover only about $7 \times 10^{-6}$ moles of helium per mole of hydrogen vaporized.

\subsection{Conclusions}

\subsubsection{Utility application}

Analysis of two types of recovery systems show that it is technically feasible to recover roughly one-third to one-half of the actual energy required for liquefying hydrogen; this, in effect, represents a cost credit for liquid hydrogen. Using shaft work only (neglecting the refrigeration capacity of liquid hydrogen), 20 to 25 percent of actual liquefaction energy can be recovered.

The biggest energy savings can be obtained if the power generating unit is a MHD generator; recovery of shaft work is attractive for gas turbine systems and, to a lesser extent, for fuel cells.

The results given here clearly show that economic analyses will be justified when hydrogen becomes an important synthetic fuel.

\subsubsection{Rare gas recovery}

Based on supply and demand considerations the only rare gas which would be worth recovering from the atmosphere is helium. However, refrigeration capacity limits the ratio of helium recovered to hydrogen vaporized to the order of $10^{-5}$. Therefore, this recovery system could not be feasible unless the cost of helium becomes extremely expensive and the demand remains high. 


\subsection{References}

[1] Strobridge, T. R., Cryogenic refrigerators - an updated survey, Nat. Bur. Stand. (U.S.) Tech. Note 655 (June 1974).

[2] Selected Topics on Hydrogen Fuel, Ed. J. Hord, Nat. Bur. Stand. (U.S.) Special Publication 419 (May 1975).

[3] McCarty, R. D. and Weber, L. A., Thermophysical properties of parahydrogen from the freezing line to $5000 \mathrm{R}$ for pressures to 10,000 PSIA, Nat. Bur. Stand. (U.S.) Tech. Note 617 (April 1972).

[4] Griffin, L., Public Service Company of Colorado, Denver, Colorado, private communication (December 1974).

[5] Chansky, S. H. and Haley, H. E., The utilization of LNG cold, Paper 68-D31 presented at the 1968 American Gas Association Operating Section Distribution Conf.

[6] Bliss, H. and Dodge, B. F., Oxygen manufacture - thermodynamic analyses of processes depending on low temperature distillation of air, Part II, Chem. Eng. Prog. 45 (2), 129 (February 1949).

[7] Springmann, H., Large air separation unit plants, ASME Paper 74-WAPID-8 (December 1974).

[8] Smith, D. E., Comparison of liquid pumping and gas compression in gasproducing oxygen plants, Book, Advances in Cryogenic Engineering $\underline{6}$, Ed. K. D. Timmerhaus, pp. 202-209, (Plenum Press, Inc., New York, N.Y., 1961).

[9] Seikel, G. R., Smith, J. N. and Nichols, L. D., $\mathrm{H}_{2}-\mathrm{O}_{2}$ combustion powered steam - MHD central power systems, Book, Hydrogen Energy, Part B, Ed. T. N. Veziroglu, pp. 969-982, (Pleñum Press, Inc., New York, N.Y., 1975).

[10] Federal Power Commission, National Power Survey, Energy Distribution Research (to be published).

[11] Baron, R., Cryogenic Systems, Book, (McGraw Hill Company, New York, N.Y., 1966).

[12] Tompkins, J. F. and Geist, J. M., Large-scale neon recovery and purification process, Book, Advances in Cryogenic Engineering 8, Ed. K. D. Timmerhaus, pp. 484-488 (Plenum Press, Inc., New York, N.Y., 1963).

[13] Ruhemann, M., The Separation of Gases, Book, (Clarendon Press, Oxford, (1949).

[14] Bliss, H. and Dodge, B. F., Oxygen manufacture-thermodynamic analyses of processes depending on low temperature distillation of air, Part I, Chem. Eng. Prog. 45 (1), 51 (1949). 
This appendix briefly describes the preliminary process design of an air separation plant which uses the refrigerating capacity of liquid hydrogen. The plant is designed to produce $8 \mathrm{~kg}$ of 99 percent pure gaseous oxygen for every $\mathrm{kg}$ of liquid hydrogen vaporized. More complete details for designing conventional air plants are given by Ruhemann [13] and by Bliss and Dodge $[14]$.

\subsubsection{Design using an atmospheric column}

Figure 2.4 shows a flowsheet for an air plant which utilizes the liquefaction energy of liquid hydrogen. The plant has one distillation column which operates at 1.0 atm and is very similar to a Linde single-column air plant. Based on the results of calculations using the availability function one would expect that air compression could be eliminated because no additional refrigeration is necessary. However, more realistic calculations show that liquid hydrogen can condense only 10 percent of the stiochiometric quantity of air. Also, heat is required in the reboiler to provide a vapor flow. Therefore, a large fraction of the air must be condensed in the column reboiler. Because air boils at a lower temperature than oxygen, the air must be compressed to roughly 3.7 atm to provide a $2.5 \mathrm{~K}$ temperature difference in the reboiler. Even so, this is lower than the $6.0 \mathrm{~atm}$ or higher required by conventional plants which derive refrigeration from gas expansion. Also, up to 40 percent of the compressor work can be obtained from the expander system described in section 2.2 .2 .

After the air is compressed it goes through the main heat exchanger where it is cooled by the product streams. Due to the hydrogen flow there is a 40 percent excess of refrigeration available in this exchanger; this is more than enough to condense the water and carbon dioxide impurities in the air. The air leaving the main heat exchanger contains 10 percent liquid; it contains one percent vapor after going through the reboiler. (To make sure there was an adequate reboiler duty for column operation, an enthalpy-composition diagram was used [13]. Air was treated as a binary mixture of oxygen and nitrogen.) The remaining vapor is condensed in the precooler and the air is expanded to 1.0 atm through a Joule-Thompson valve. It then enters the column as a saturated liquid.

The nitrogen-rich-stream, which contains 7 percent oxygen, leaves the column as a vapor, goes through the precooler and then through the main heat exchanger (the heat duty of the precooler is based on a minimum temperature difference of $2 \mathrm{~K}$ ). The oxygen comes off of the bottom of the column as a liquid and is compressed to the desired product pressure. It is possible to compress the oxygen to a higher pressure and then expand the ambient temperature gas to the final pressure. However, the net work out of this expander is probably too small to justify this system if the final oxygen pressure is much greater than $1.0 \mathrm{~atm}$. For these calculations, the pump was taken to be 80 percent efficient based on adiabatic compression.

The liquid hydrogen is first compressed to $200 \mathrm{~atm}$ before going to the precooler. It enters the precooler at roughly $28 \mathrm{~K}$ because it has been warmed by the compression (again assuming an 80 percent of adiabatic pump efficiency). The hydrogen then goes through the main heat exchanger before it is expanded to the desired outlet pressure. The net work from the expander is used in the air compressor. 


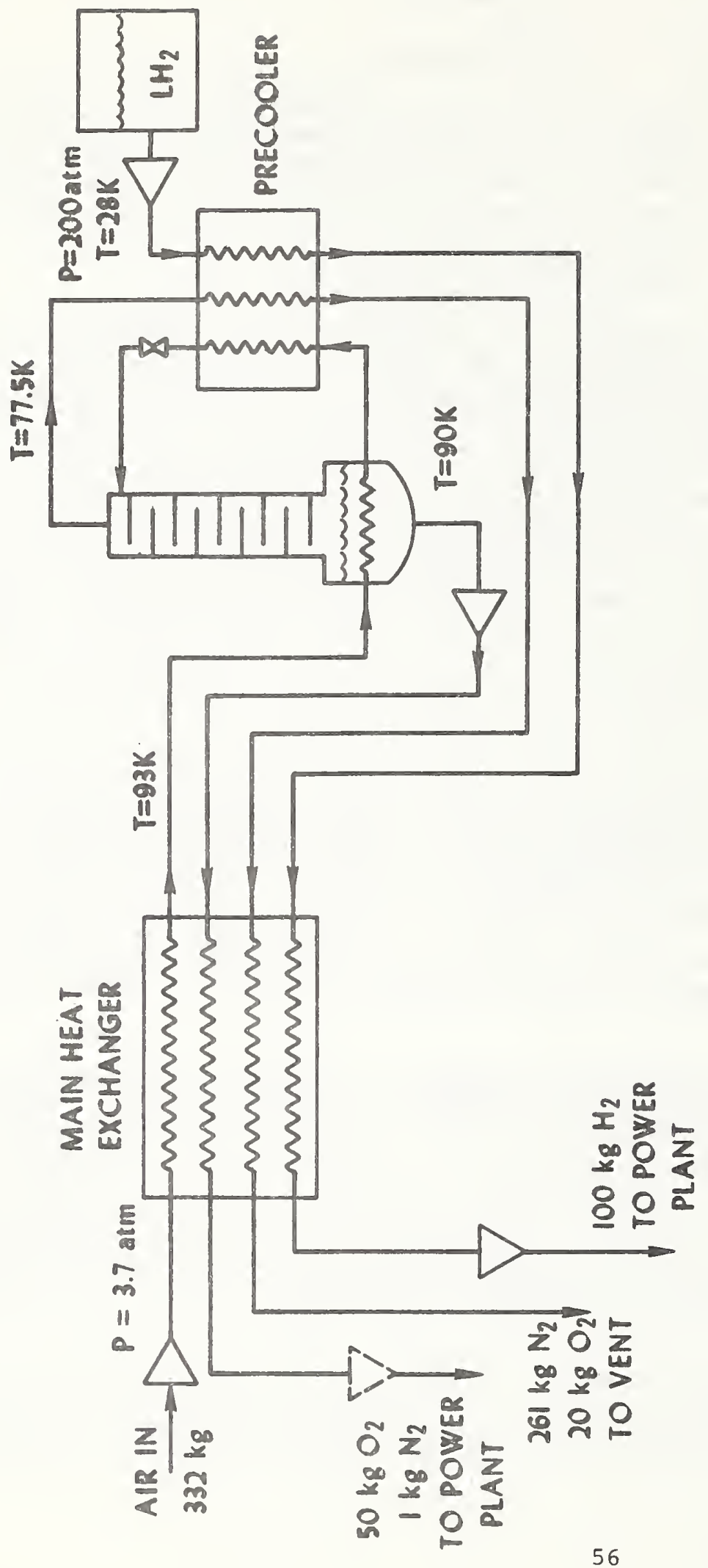

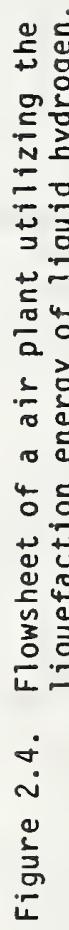




\subsubsection{Subatmospheric column}

The primary attraction of using a subatmospheric column is the reduction of inlet air pressure. If the column operates at $1 / 3 \mathrm{~atm}$ the inlet air has to be compressed to roughly $1.6 \mathrm{~atm}$ to provide a $2 \mathrm{~K}$ temperature difference across the reboiler. However, this advantage is somewhat offset by the work required to compress the nitrogen-rich stream back to $1.0 \mathrm{~atm}$. Since the nitrogen stream should be compressed at low temperatures to minimize the work, there will be some loss of refrigeration due to compression. In fact, by assuming an 80 percent of adiabatic efficiency for the compressor, there is very little excess refrigeration available in the main heat exchanger.

Also, it has been assumed that the air plant is leak tight; if vacuum pumps are needed, the advantage of subatmospheric operation could disappear. 
NBS-114A (REV. 7-73)

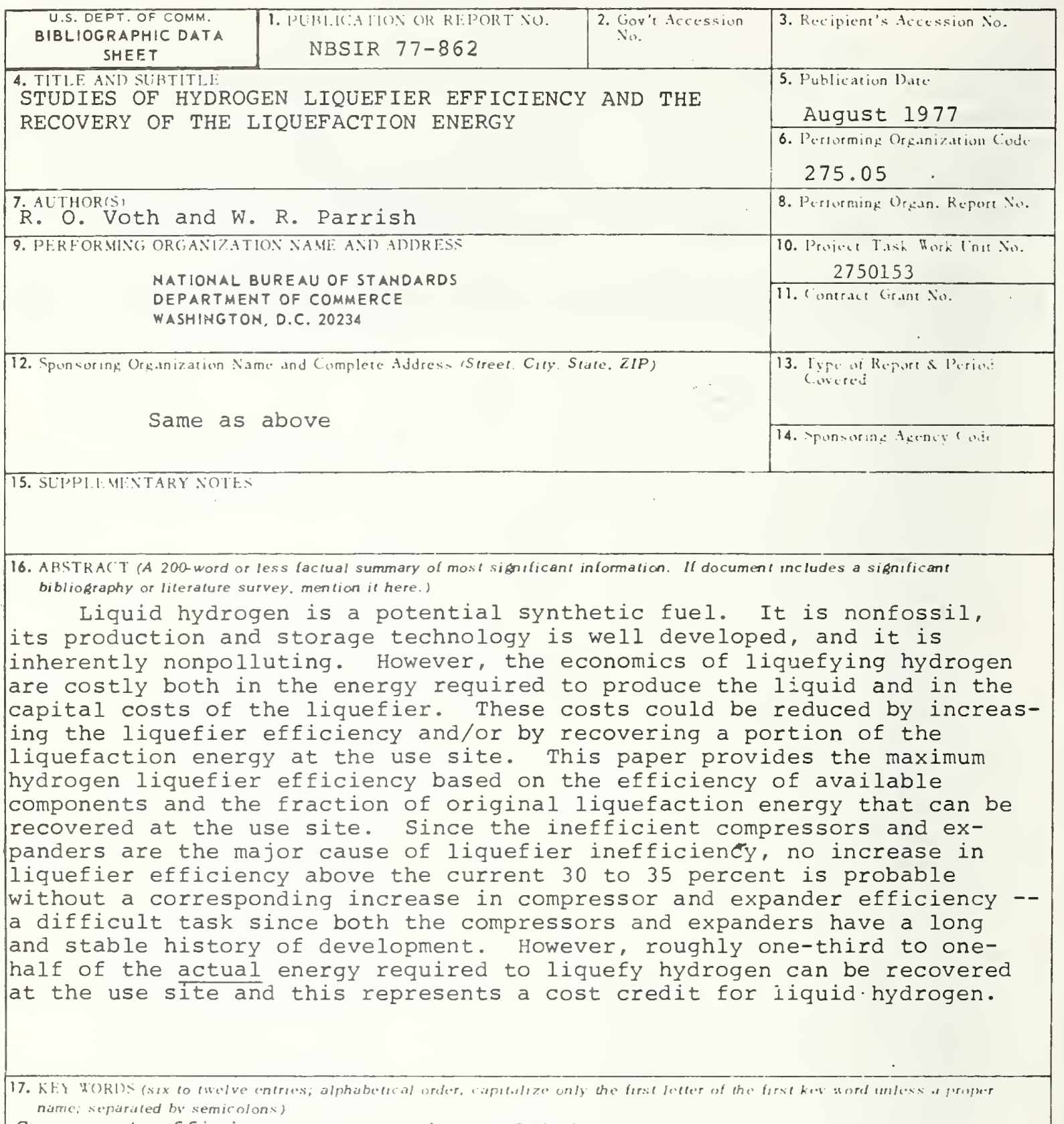

Component efficiency; cryogenics; efficiency; energy recovery; hydrogen; liquefier.

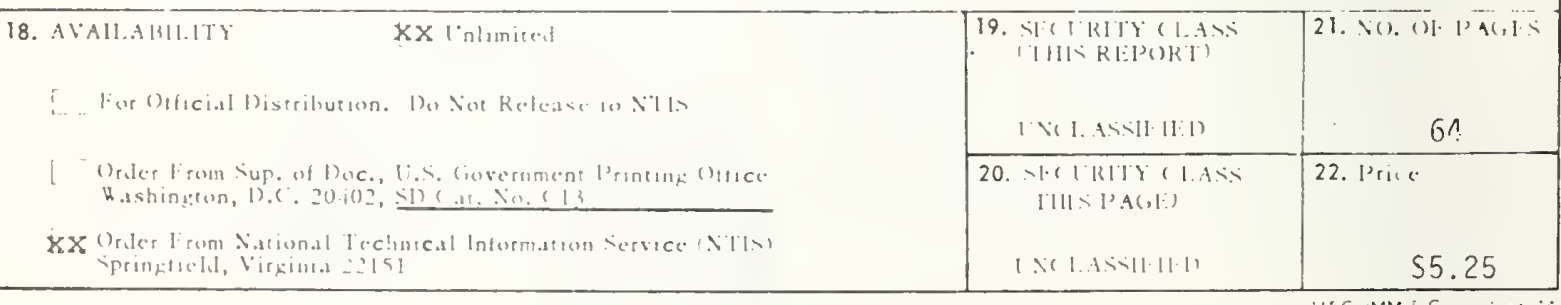





MNERT 
